\section{Journal of Educational}

and Psychological Sciences

Volume (6), Issue (8): 28 Feb 2022

P: 20 - 35

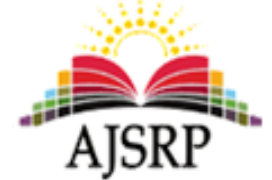

ISSN: 2522- 3399

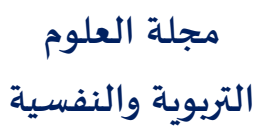

المجلد (6)، العدد (8): 28 فبراير 2022 م

ص: 20 - 35

\title{
The degree to which high school administrators manage the educational crisis in Ajloun province under the Corona pandemic from the point of view of teachers
}

\author{
Alaa Kamal Sami Momani \\ Ministry of Education || Jordan
}

\begin{abstract}
The purpose of the study was to determine the degree to which secondary school administrators practiced managing the educational crisis in Ajloun province under the Corona pandemic from the point of view of teachers. The researcher used the analytical descriptive curriculum, using the resolution study tool distributed to a group of school teachers in Ajloun province. (93) Teachers selected in a simple, random manner. The study found the following findings. The results of the study showed the degree to which high school administrators practiced to manage the educational crisis in Ajloun province in the Corona pandemic, from the point of view of teachers. 3.411 That is, the degree of consent readiness (average), and the absence of statistically significant differences between the computational averages of the responses of sample members to the tool as a whole attributable to variables (gender, experience), In the light of the findings, the researcher recommended that all schools should be equipped with the appropriate tools, tools and various equipment to help manage and respond to the crisis in a more effective manner, and that appropriate channels of communication and communication should be put in place between the components of the educational process and the various departments in order to respond to and manage crises effectively and with high capacity.
\end{abstract}

Keywords: High school administrators, educational crisis, the Corona pandemic, crisis management.

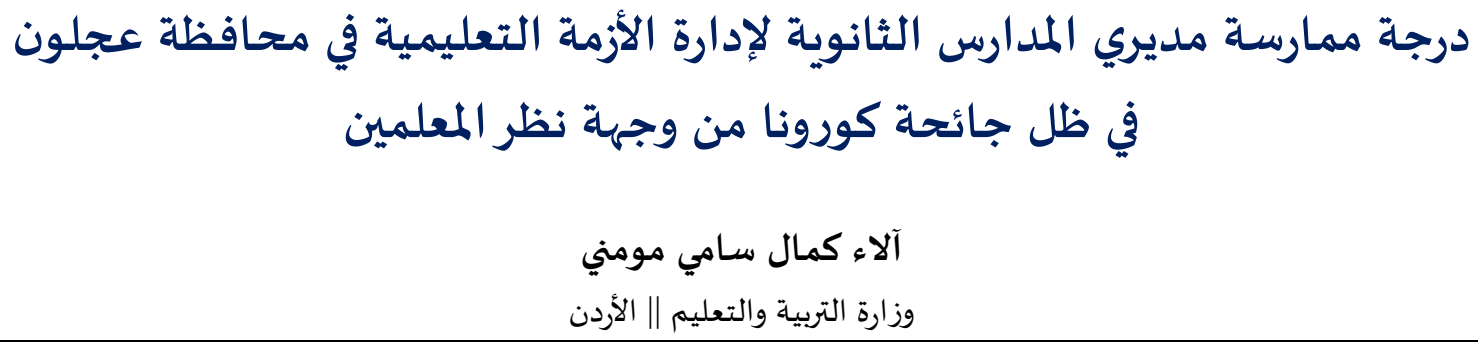

المستخلص: هدفت الدراسة للتعرف على درجة ممارسة مديري المدارس الثانوية لإدارة الأزمة التعليمية في محافظة عجلون في ظل جائحة كورونا من وجهة نظر المعلمين، استخدمت الباحثة المنهج الوصفي التحليلي، والاستبانة كأداة تم توزيعها على مجموعة من المعلمين والمعلمات في المدارس في محافظة عجلون والبالغ عددهم (93) معلماً ومعلمة، تم اختيارهم بالطريقة العشوائية البسيطة،

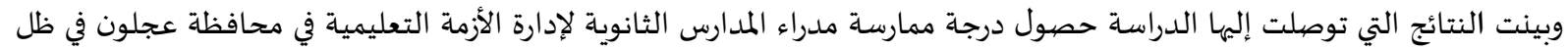

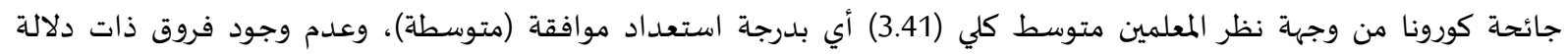

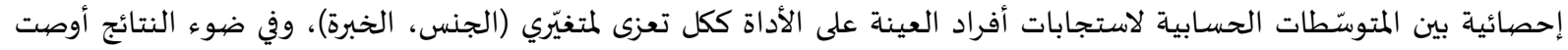

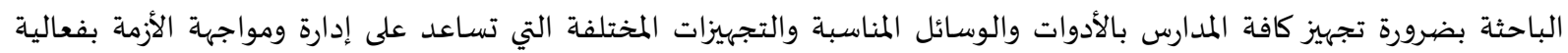
عالية، وتفعيل قنوات الاتصال والتواصل المناسبة بين عناصر العملية التعليمية والإدارات المختلفة لمواجهة وإدارة الأزمات بفعالية وقدرة عالية، الاستفادة من تجارب الدول المتقدمة في إدارة الأزمات التعليمية بنجاح المباح. 
يشهد الميدان التربوي العديد من التغيرات، ولمدير المدرسة الدور الكبير في مسايرة هذه التغيرات ومواكبتها؛ إذ يفترض بمدير المدرسة أن يمتلك رؤية واضحة للتعامل مع هذه التغيرات المتصارعة نتيجة أزمة كورونا ومنها إدارة

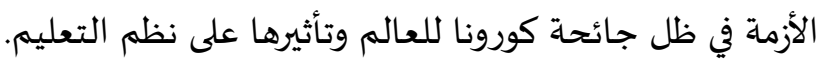

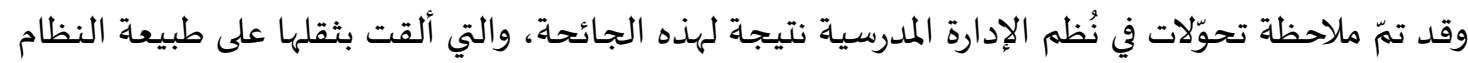

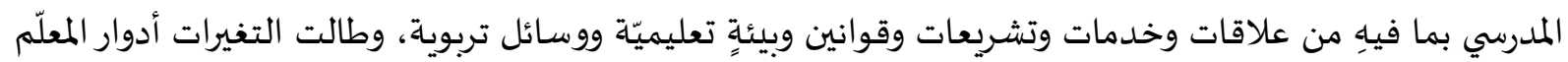

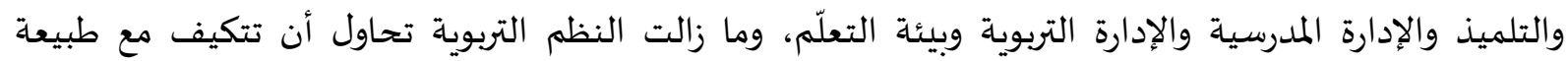

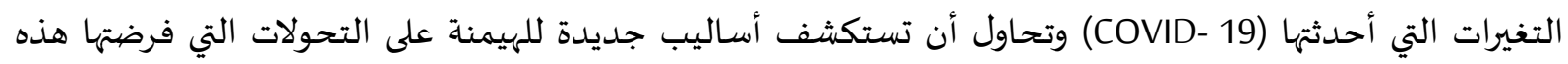

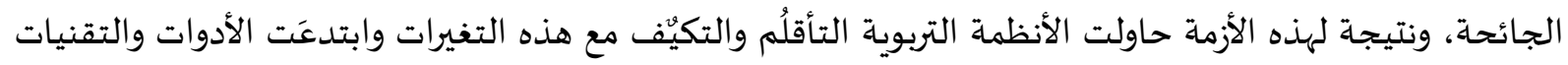

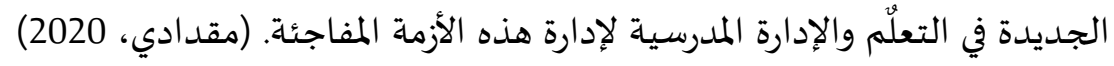

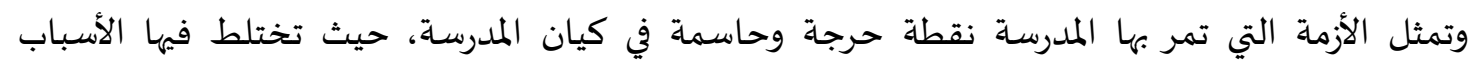

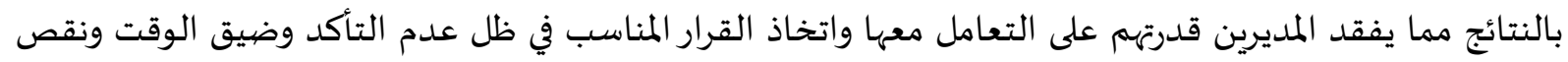

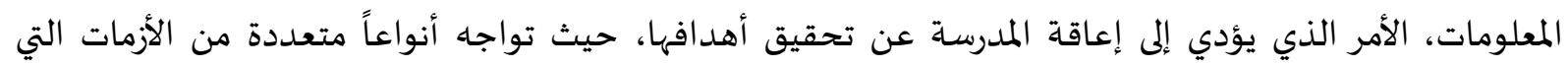

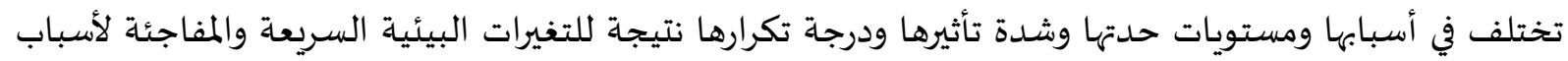

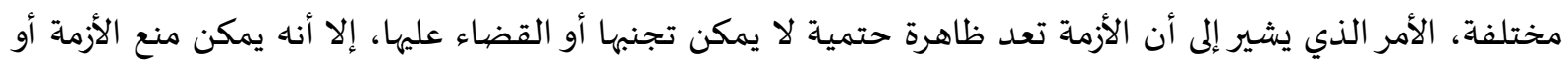
الحد من آثارها السلبية عن طريق إدارة الأزمات (اليحيوي، 2006).

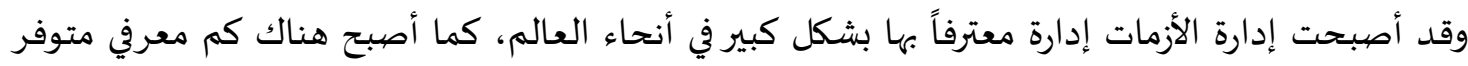

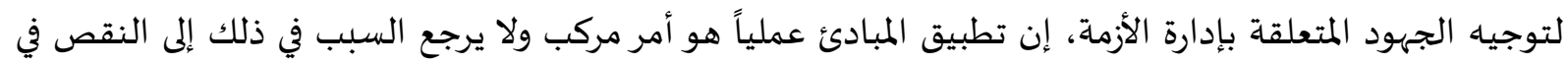

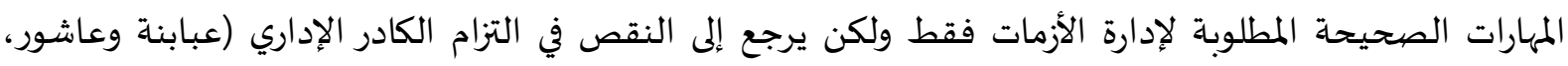

وفي ظل انتشار فيروس كورونا المستجد الذي شكل جائحة عالمية؛ عانت منها مختلف دول العالم، أصبح

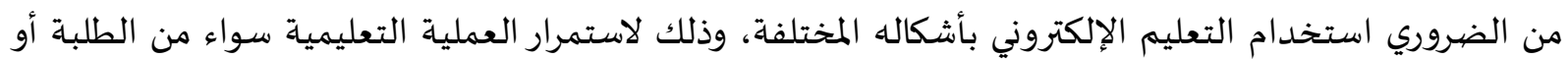

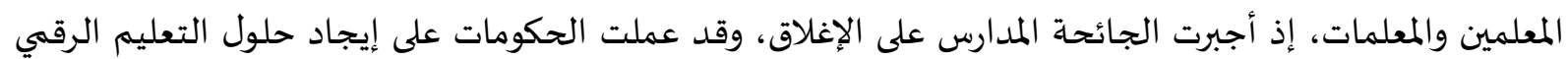
لتوفير مستوى من الاستمرارية في مثل هذه الأزمات ويعد ظهور التعليم الالكتروني والتعليم عن بعد استجابة حقيقية

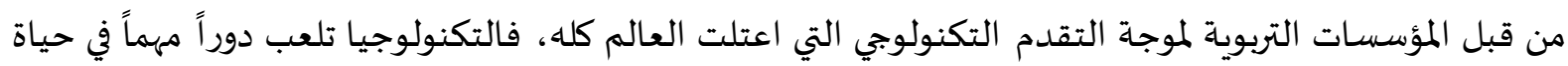

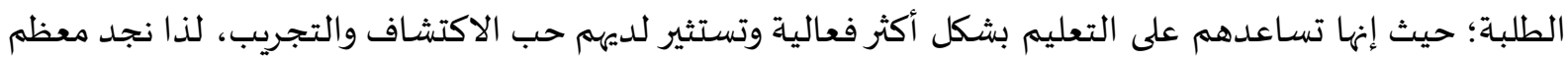

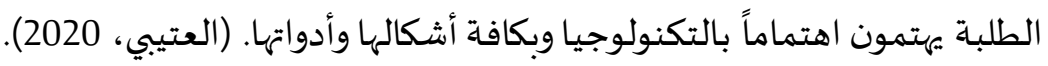

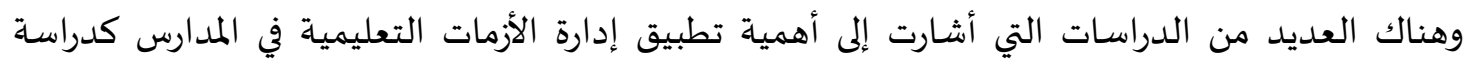
القرني وشريف (2021)، ودراسة مقدادي (2020)، ودراسة المطيري (2019).

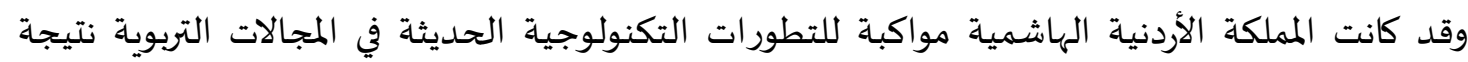

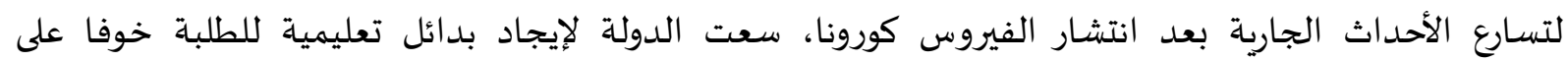

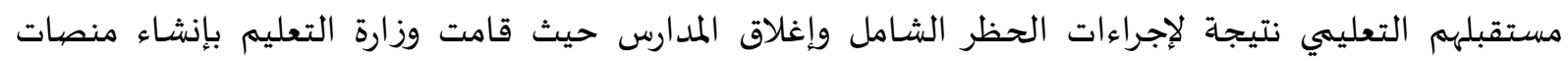

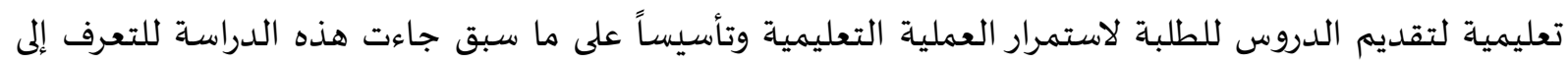


درجة ممارسة مديري المدارس الثانوية لإدارة الأزمة التعليمية في محافظة عجلون في ظل جائحة كورونا من وجهة نظر المعلمين.

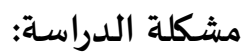

تتعرض مدارس التعليم الثانوي في الأردن كفيرها من مدارس التعليم الثانوي بدول العالم المختلفة لكثير من

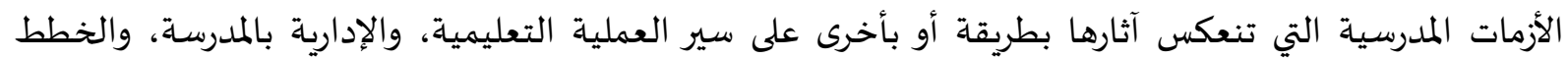

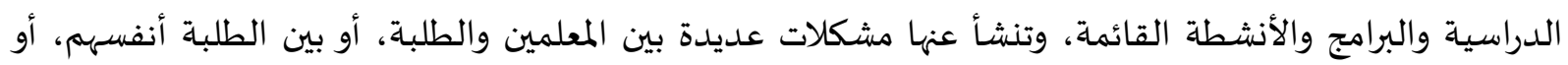

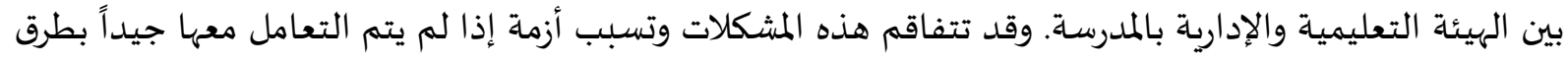

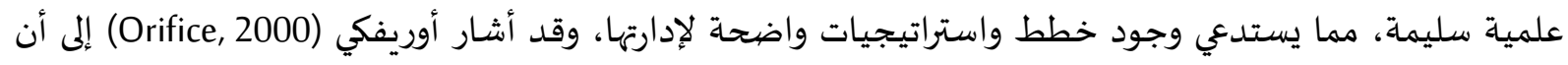

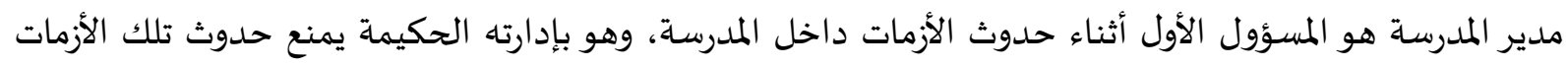

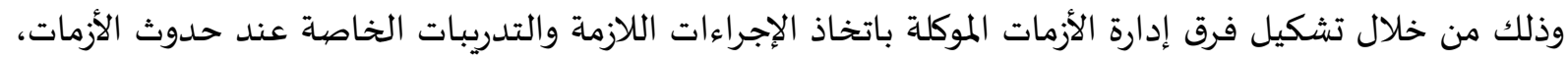

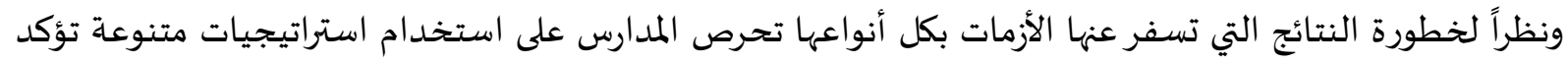

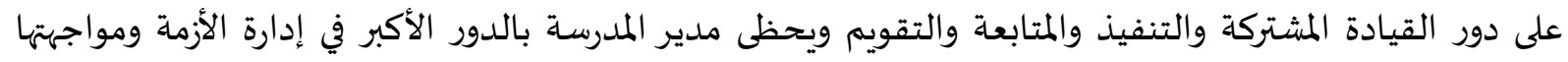

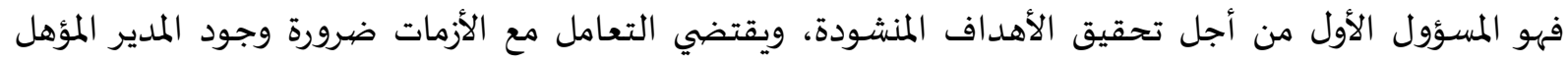

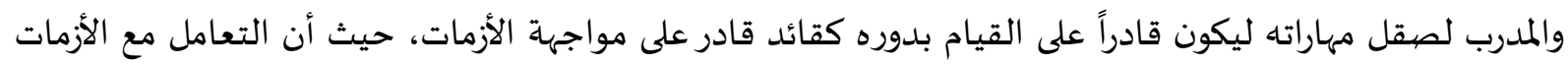

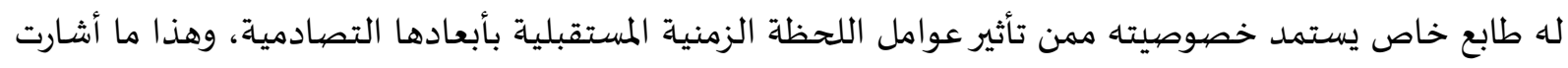

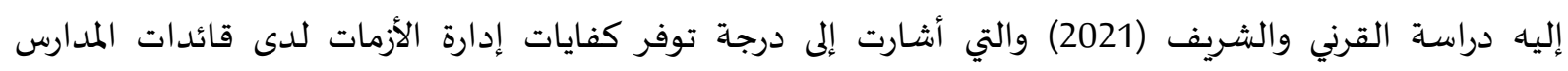

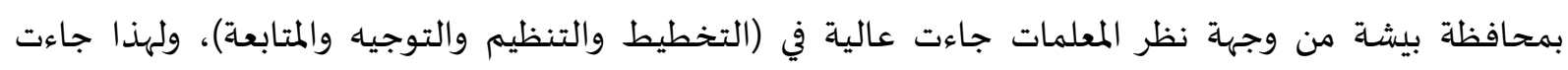

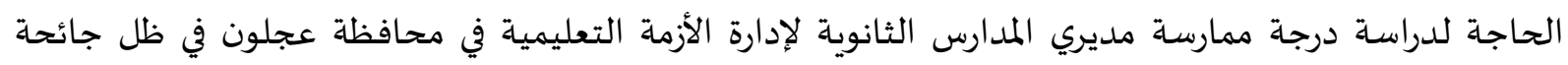
كورونا من وجهة نظر المعلمين.

أسئلة الدراسـة: (c)

بناء على ما سبق؛ تتبلور مشكلة الدراسة في السؤالين الرئيسين الآتيين:

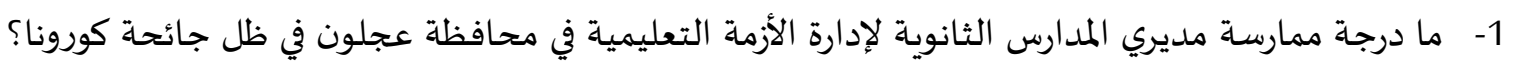

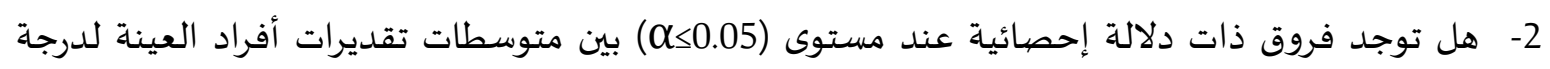

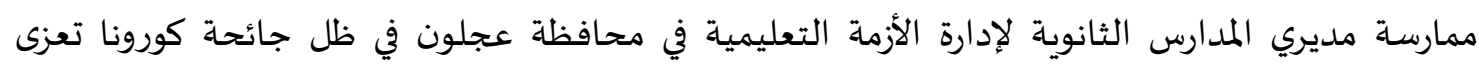

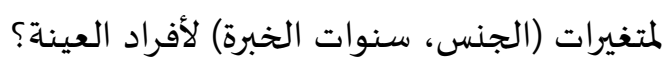

أهداف الدراسة:

تسعى الدراسة الحالية لتحقيق الأهداف الآتية:

1- التعرف على درجة ممارسة مديري المدارس الثانوية لإدارة الأزمة التعليمية في محافظة عجلون في ظل جائحة

كورونا.

2- التعرف على مدى استعداد مدراء المدارس لإدارة الأزمة التعليمية في محافظة عجلون في ظل جائحة كورونا

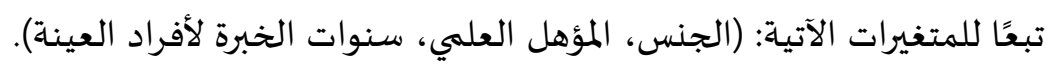


تكمن أهمية الدّراسـة من جانبين هما:

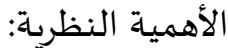

تكتسب الدّراسة أهميتها من أهمية الموضوع الذي تتناوله وهو درجة ممارسة مديري المدارس الثانوية لإدارة

الأزمة التعليمية في محافظة عجلون في ظل جائحة كورونا.

تقديم إطار نظري شامل حول إدارة الأزمة التعليمية يمكن الرجوع إليه من قبل صانعي القرار والمختصين والباحثين في الشأن التربوي.

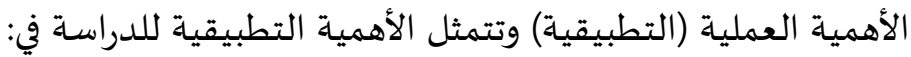

تقديم توصيات قد تسهم في تحسين دور الإدارة المدرسية في إدارة الأزمات التعليمية واستمرار العملية

التّعليمية بشكل أفضل، ومواكبة التغيرات مع الحفاظ على توازن سير العملية التّعليمية.

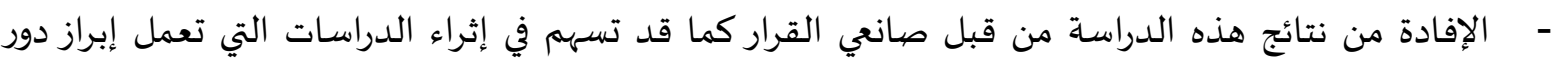

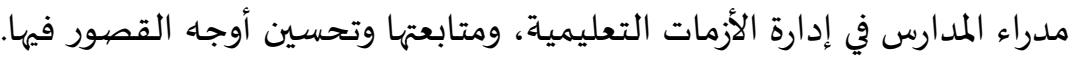

حدود الدراسة

تم إجراء الدّراسة ضهمن الحدود الآتية:

الحدود الموضيوعية: درجة ممارسة مدراء المدارس الثانوية لإدارة الأزمة التعليمية في ظل جائحة كورونا. الحدود البشرية: معلمي ومعلمات المدارس الحكومية.

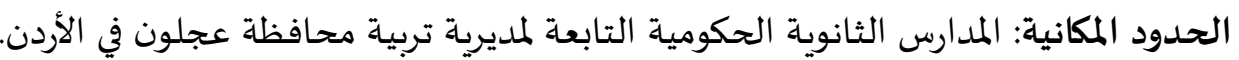

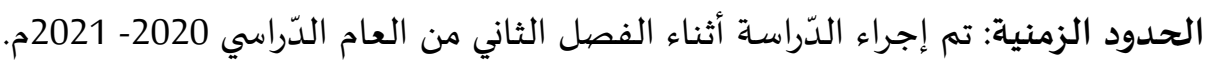

مصطلحات الدراسة: - الأزمة: " موقف يحدث خللاً يؤثر تأثيراً مادياً على سير العمليات الحيوية أو سلوك الأعمال ويتسم بالتهديد

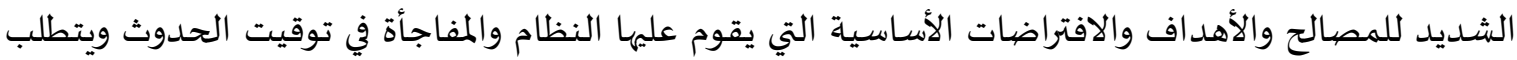

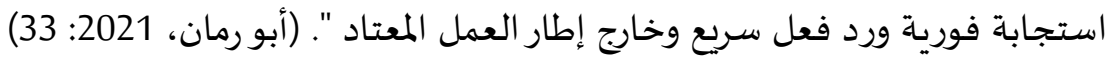
- الأزمات التربوية: "حالة من الخلل والاضطراب تؤدي إلى حدوث خلى خلل في نظام المؤسسة التعليمية اليومي وتعيق

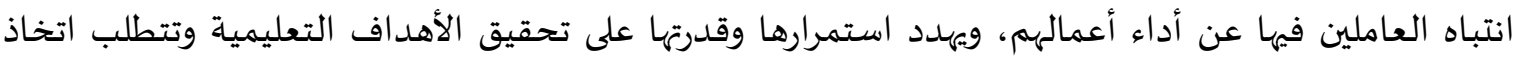

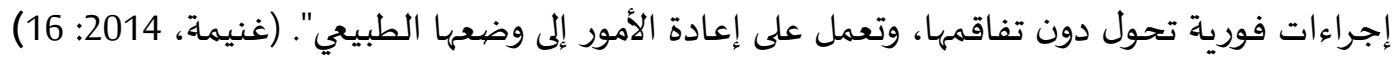

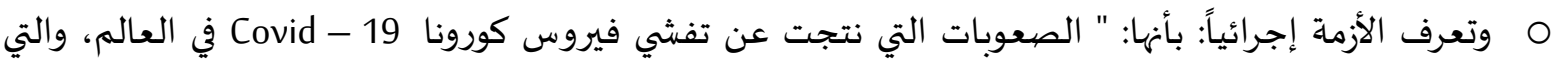

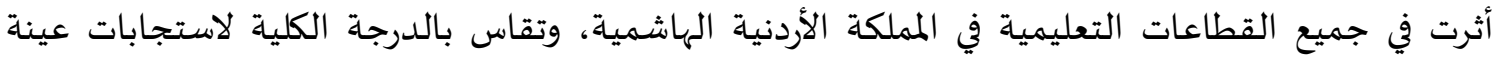

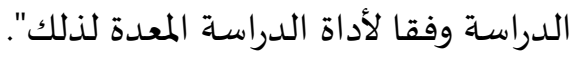
- إدارة الأزمات التربوية: "هي تقنية لمواجهة الحالات الطارئة والتخطيط للتعامل مع الحالات التي لا يمكن تجنها،

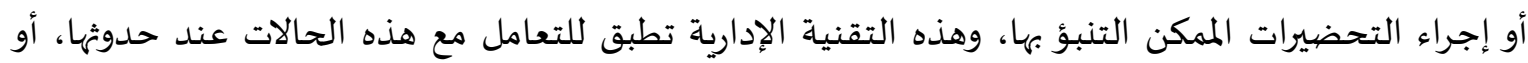

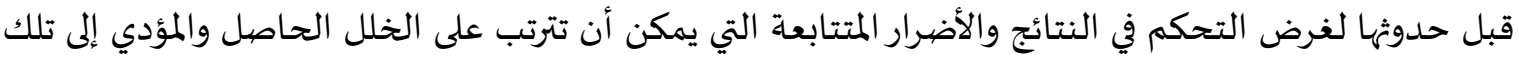

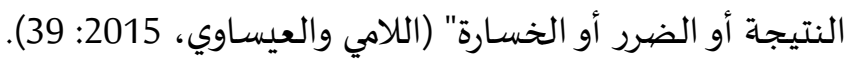


O متعريف إدارة الأزمات إجرائيًا: هي المتطلبات أو الآليات التي يستخدمها مديرو المدارس الثانوية في إدارة الأزمة

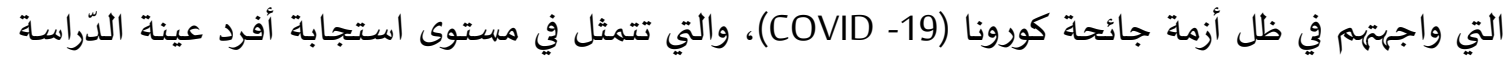
على فقرات أداة الدّراسة. - مدراء المدارس: " الشخص المعين رسمياً من وزارة التربية والتعليم بوظيفة مدير مدرسة، ليكون مسؤولاً مباشراً

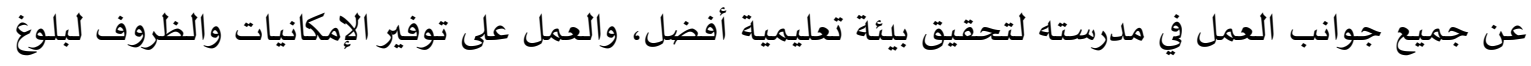

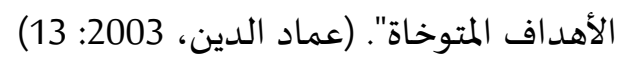

O ويعرف إجرائياً بأنه الشخص الذي يقود الإدارة المدرسية ويقوم بعملية توجيه أعمالها والإشراف عليها

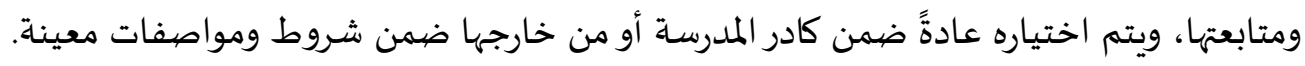

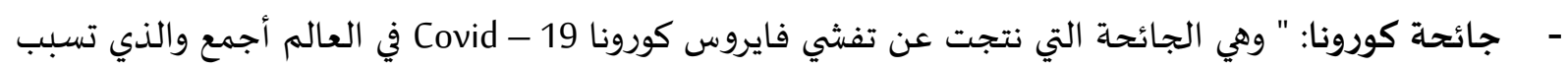

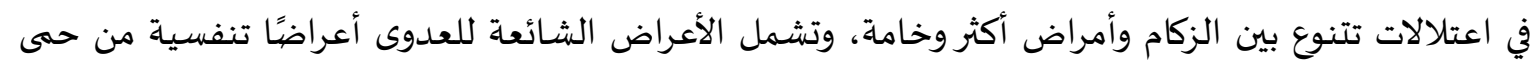

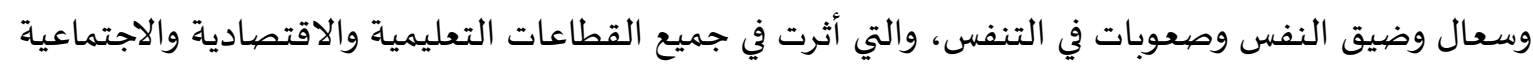

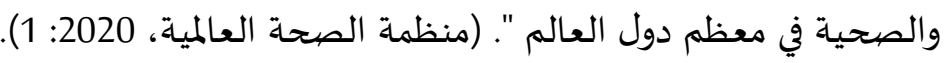

2- 2 - الإطار النظري والدراسـات السابقة. أولاً - الإطار النظري: أشتمل الأدب النظري على موضوعات تتعلق بمفهوم الأزمة وأنواعها، ومعيقاتها، ودور مدراء المدارس وفاعليتهم في إدارة الأزمات في المدرسـة:

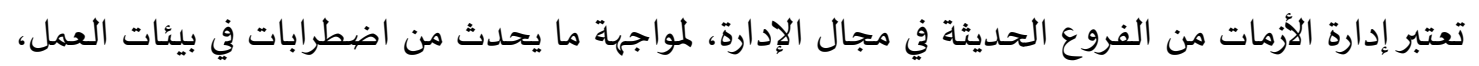

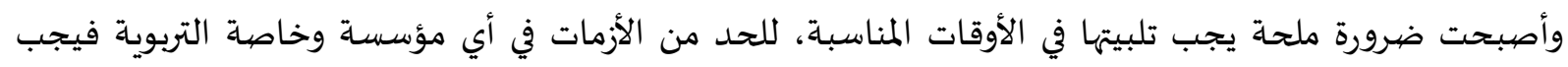

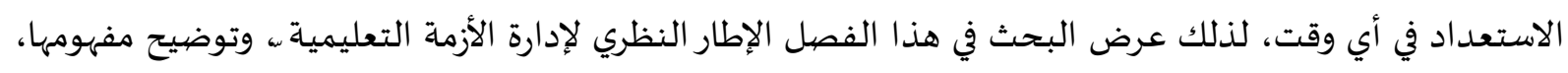

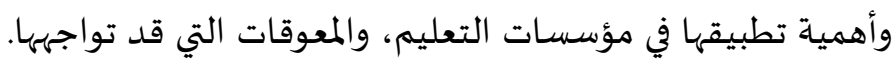

مفهوم الأزمة: اصطلاحاً عرفها الخضيري بأنها: " موقف وحالة يواجهها متخذ القرار في أحد الكيانات الإدارية (دولة ن

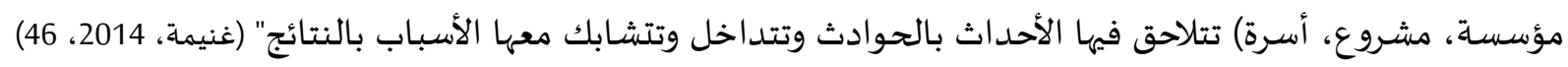

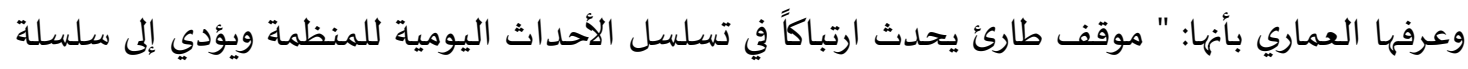

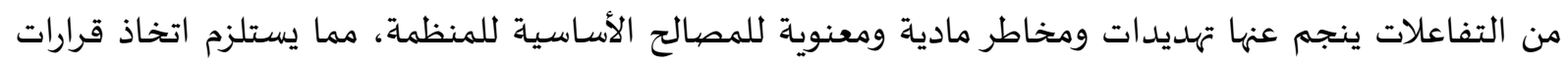

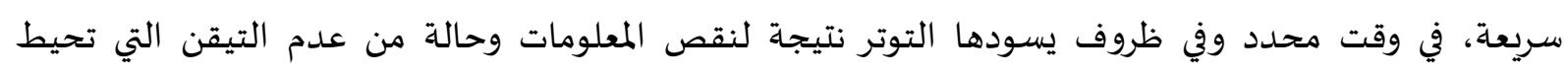
بأحداث الأزمة" (العال، في وقت محدد وفي فروف

مفهوم الأزمة التعليمية: - م هناك اختلافات بسيطة بين مفهوم الأزمة التعليمية ومفهوم الأزمة بشكل عام، باعتبار التعليم منظمة

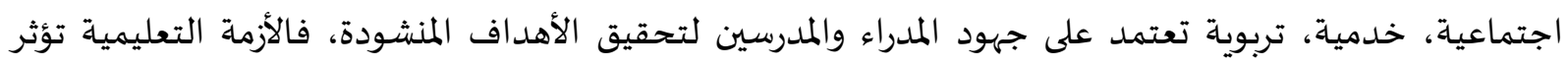

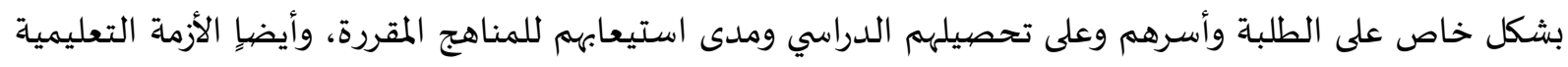


تؤثر على المدرسين وعلى الدافع والمبادرة لديهم، وأيضياً تؤثر الأزمة التعليمية على الدافعية والمبادرة للمدراء والمعلمين.

$$
\text { - معدل تكرار الأزمة (البعد الزمني): }
$$

أزمة تعليمية متكررة: وهي التي تأخذ طابع التكرار ويمكن توقعها من قبل القائمين على العمل، فيحاول

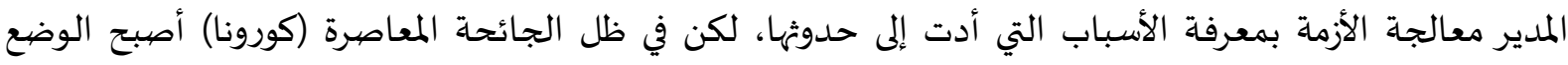

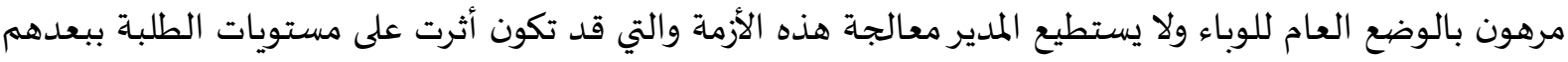

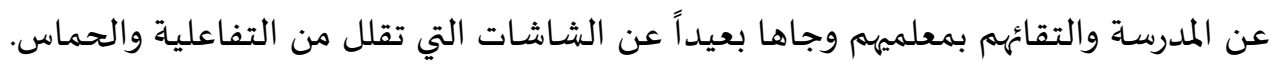

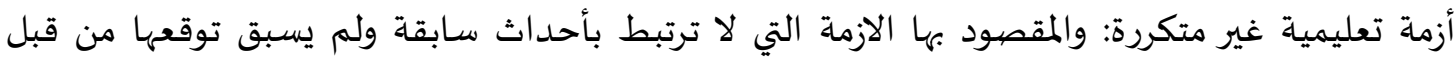

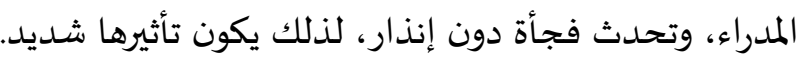

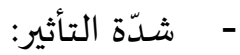

أزمة تعليمية ظرفية هامشية محدودة التأثير: وهي الأزمة التي تحدث بسبب ظروف تترك نتائج وعواقب كبيرة، ويتم معالجتها بتعديل أساليب السياسات وأساليب العمل المستخدمة في في المؤسسات

أزمة تعليمية جوهرية هيكلية التأثير: وهي التي تؤثر على المؤسسة بشكل كامل، بجميع الجوانب المادية

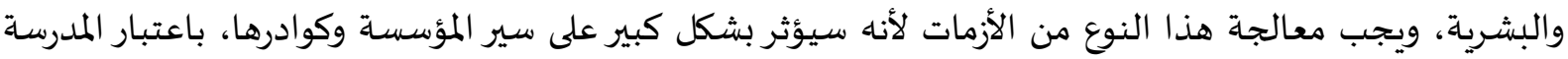

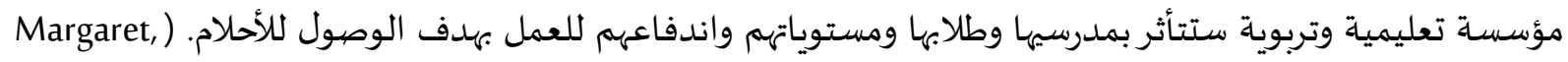

$$
\text { - }
$$

أزمة تعليمية جزئية: والمقصود بها الأزمة التي تحدث في المستومية قطاع أو قسم أو جزء معين، ولا تؤثر على باقي

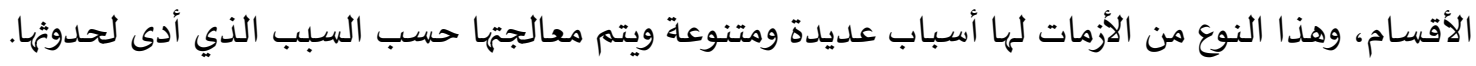

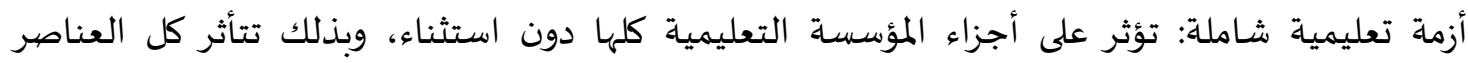

التعليمية، وتعتبر أزمات شاملة أسباب حدوثها عامة وليس لها أسباب معينة. (Muro \& Kottman, 2005)

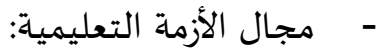

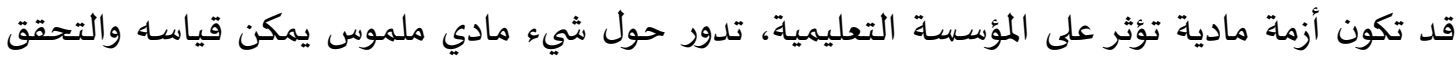

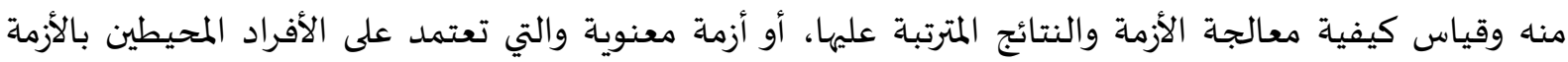
كالثقة والتفاهم بين الأفراد. والنوع الآخر أزمة معنوية: والتي تعتمد على الأفراد المحيطين بالأزمة كالثقة والتفاهم وهذا النوع من الأزمات يتم معالجته بصعوبة نظراً لعدم وجود شيء ملموس، والاعتماد على المضيمون. (Stanimirova et al, 2017)

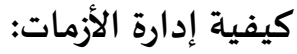

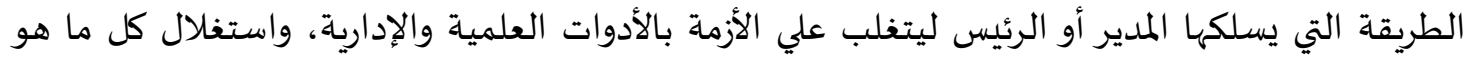

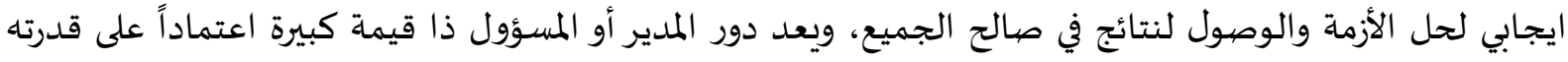


في التنبؤ للأزمات المحتملة قبل حدوثها عن طريق رصد المتغيرات البيئية من داخل وخارج بيئة العمل، والإعداد

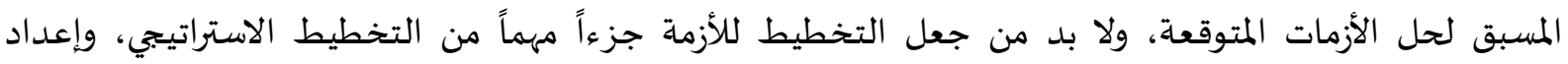

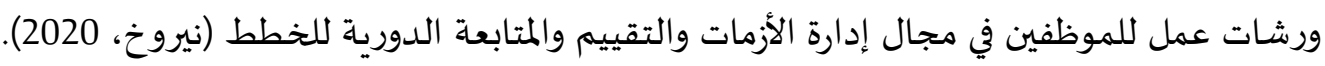

أهمية إدارة الأزمة التعليمية:

تتم عملية إدارة الأزمات من قبل المدير، فيعمل على محاولة الوصهول إلى حل حتى لا تؤثر الأزمة على بيئة

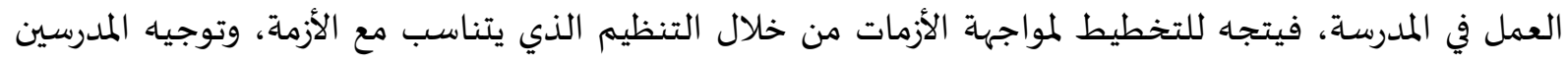

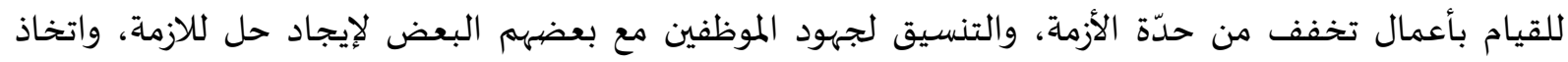

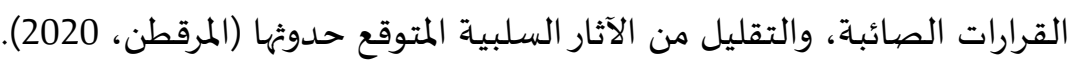

دور مدير المدرسة في إدارة الأزمات المدرسية

تمر الأزمة بثلاث مراحل كما وردت في دراسة (خليل، 2016)

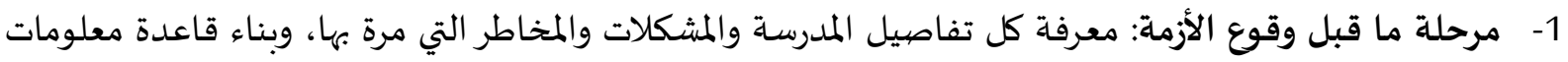

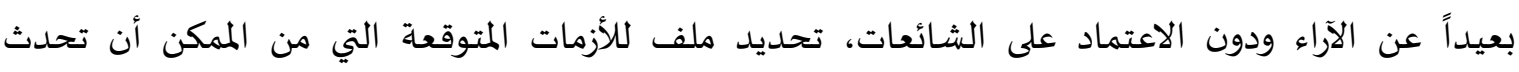
ومقترحات لعلاج الأزمة في حال حدونها وتحديد دور كل شخص الاعت في المعالجة، الاهتمام بكافة الامور حتى وان

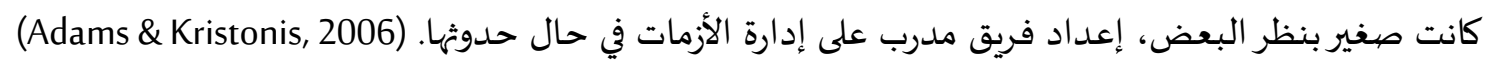

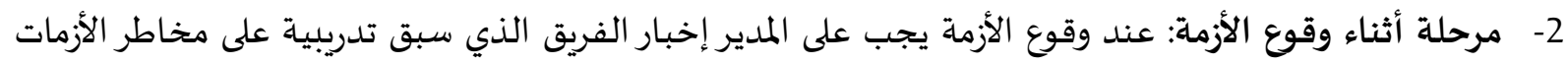

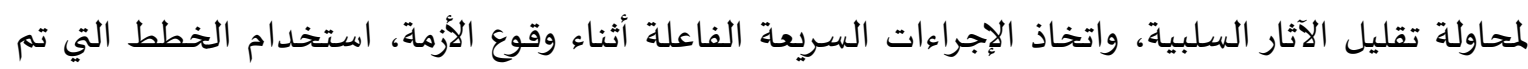

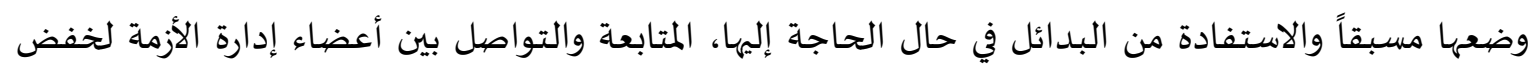

حالة التوتر. (Oredein, 2010)

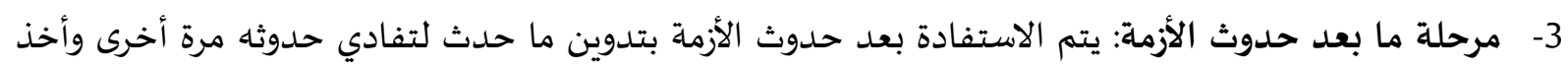

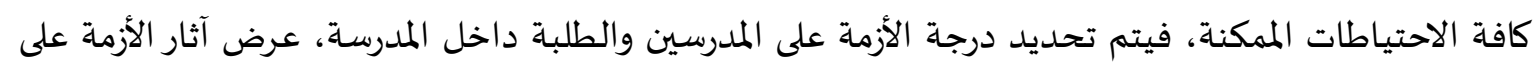

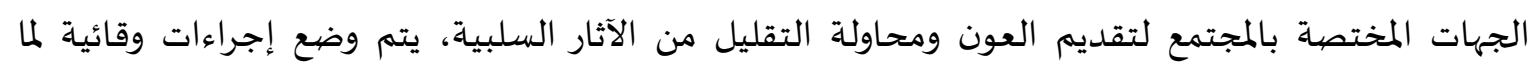

سيحدث بعد الأزمة. (Stanimirova et al, 2017)

ثانياً- الدراسات السابقة: - أجرى القرني وشريف (2021) دراسة هدفت إلى التعرف على درجة توفُّر كفايات إدارة الأزمات لدى قائدات

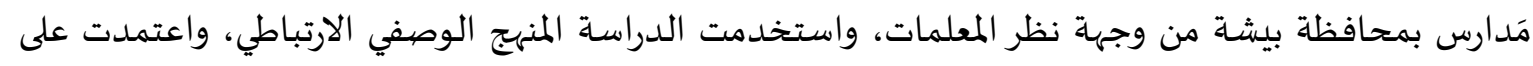

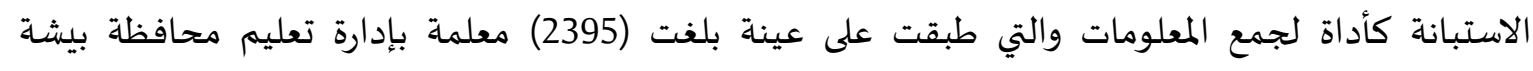

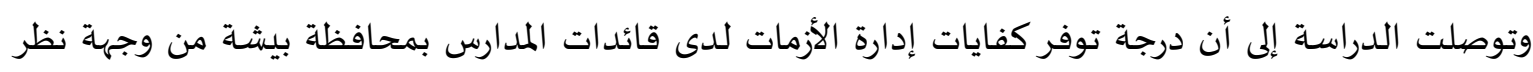

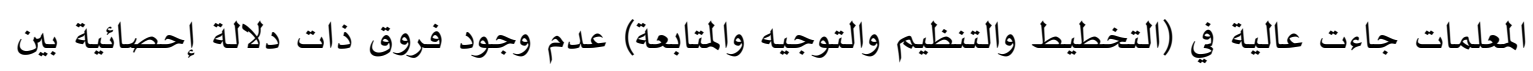

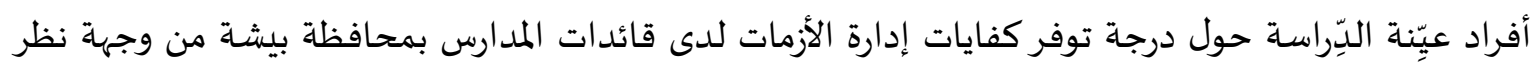

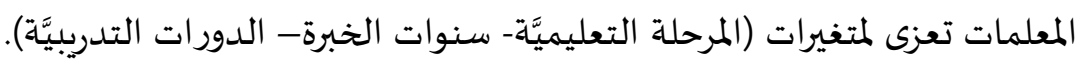

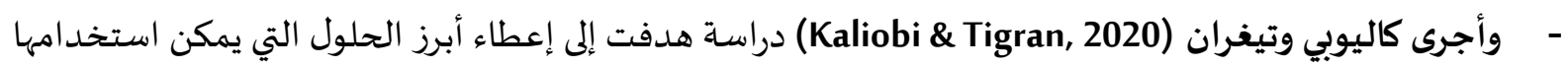

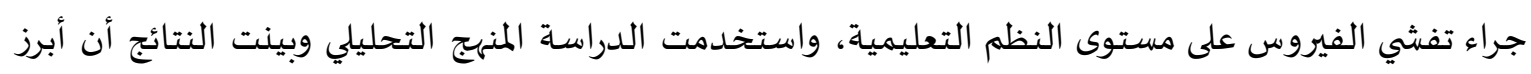

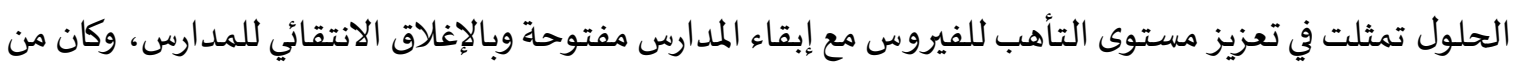


أبرز الاستراتيجيات استخداماً هو إغلاق المدارس على المستوى الوطني والاستعانة بمصادر التعلم والتعليم عن بعد

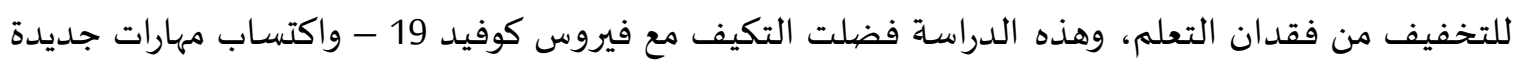

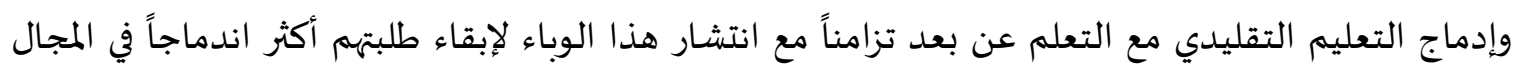

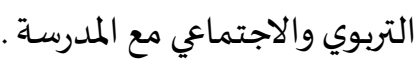
أشار مصطفى(Mustafa, 2020) في دراسته إلى أثر جائحة فيروس كورونا على النظم التعليمية لعام - 2019

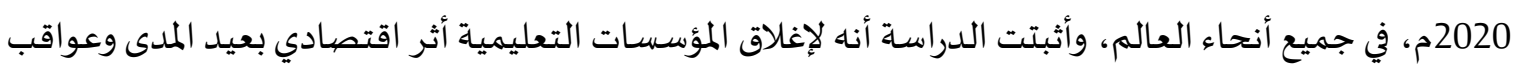

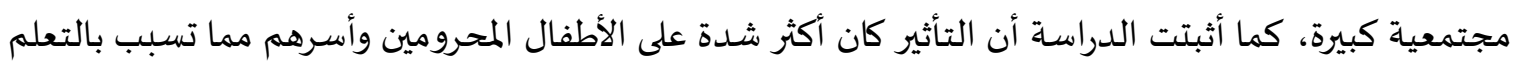

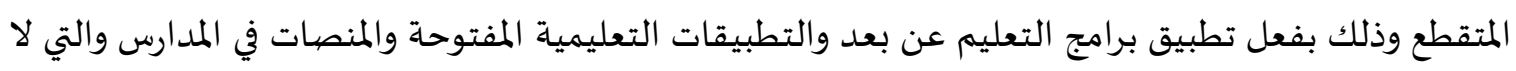

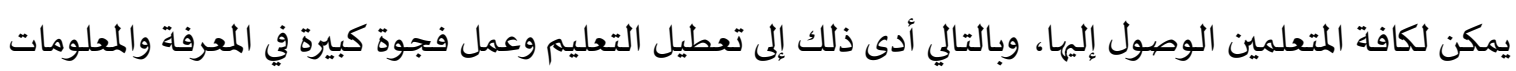

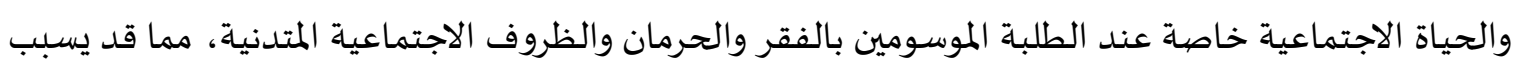
لهم انقطاع تام عن التعليم.

وأجرى مقدادي (2020) دراسة هدفت إلى الكشف عن تقديرات معلمي الدراسات الاجتماعية لدرجة تطبيق إدارة الأزمات في المدارس الحكومية في لواء قصببة إبرد، تم استخدام المنهج الوصفي التحليلي، والاستبانة أداة

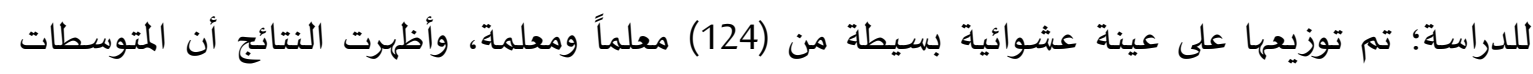

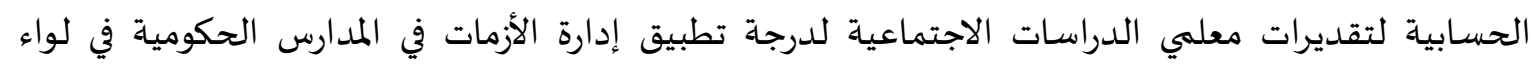

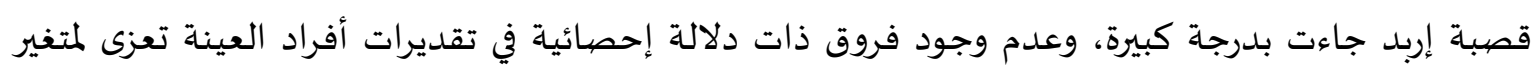
الجنس. وفي دراسة أجرتها منظمة هاندرد (Hundred Organization, 2020) هدفت إلى فهم المشكلة التي تواجه

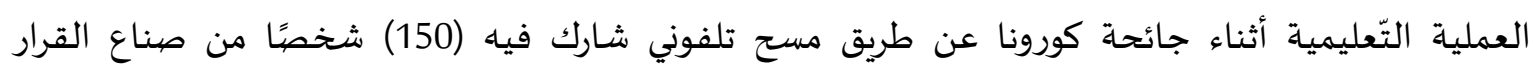

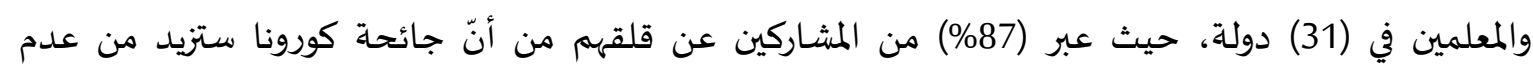

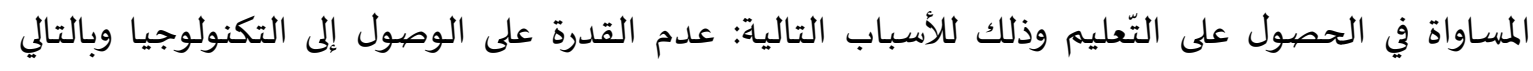

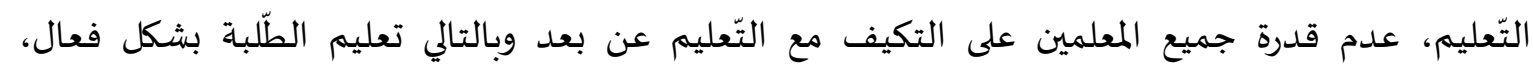

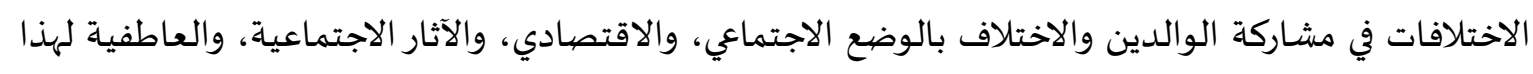

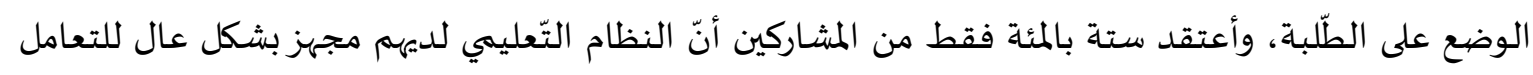

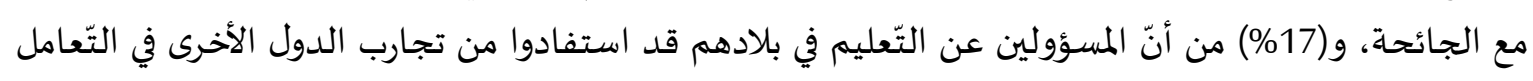
مع الأزمة. وأجرى المطيري (2019) دراسـة هدفت إلى التعرف على درجة تطبيق إدارة المخاطر في مدارس المرحلة المتوسطة

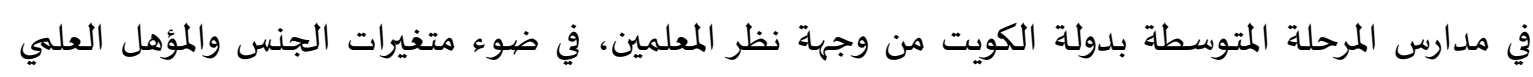

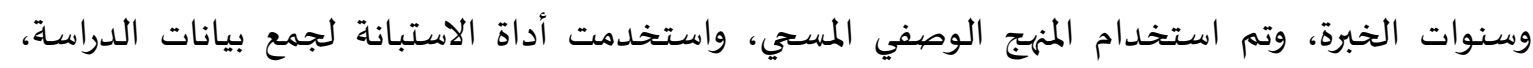

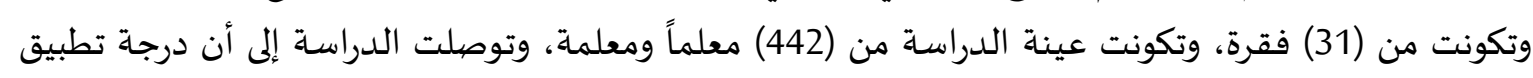

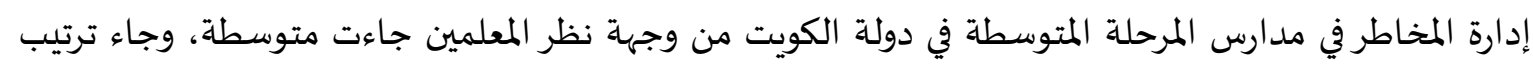

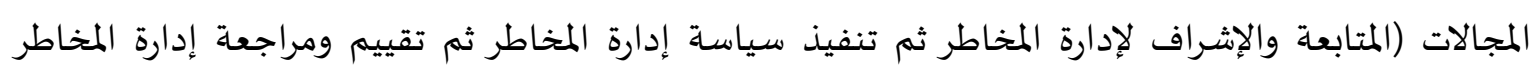

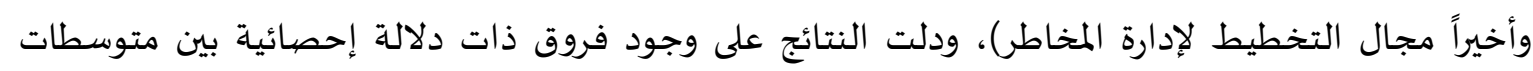

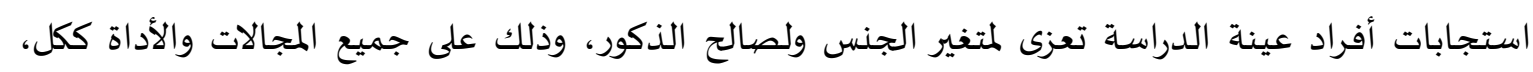

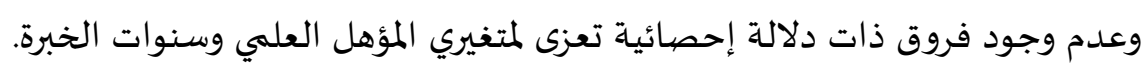


- وأجرى المشاقبة (2018) دراسة هدفت إلى الكشف عن درجة امتلاك مديري المدارس الحكومية في مدارس

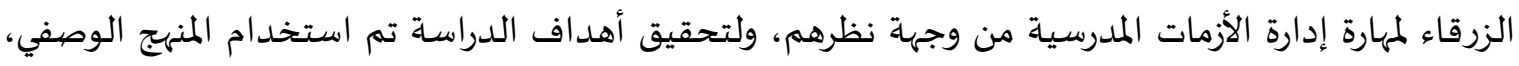

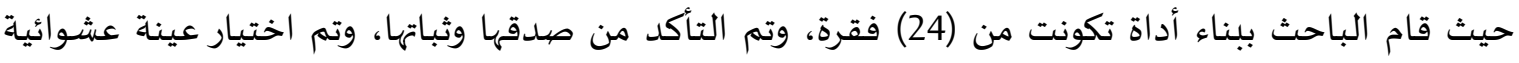

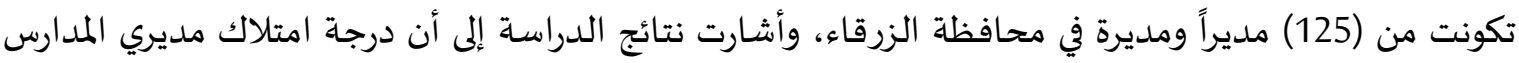

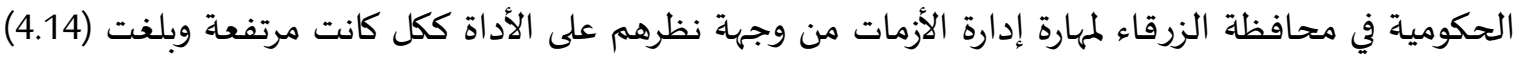

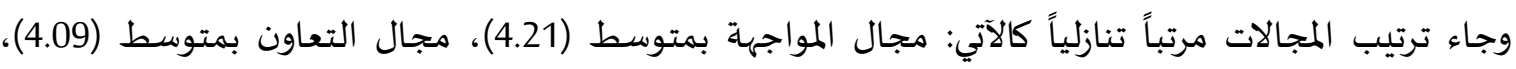

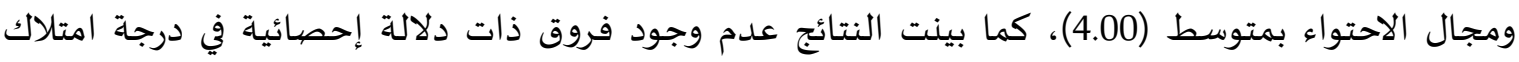

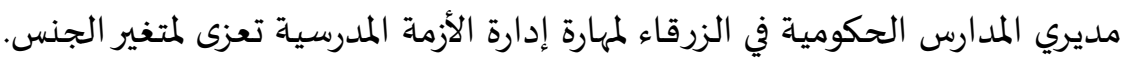
وفي دراسة أجرتها دايغتري (Daughtry, 2015) هدفت لمعرفة استعداد مديري المدارس للتعامل مع الأزمات

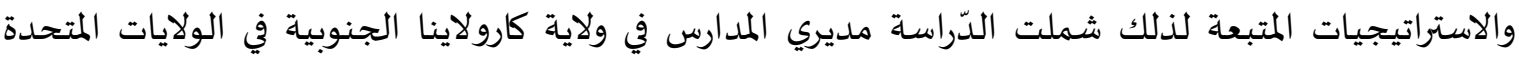

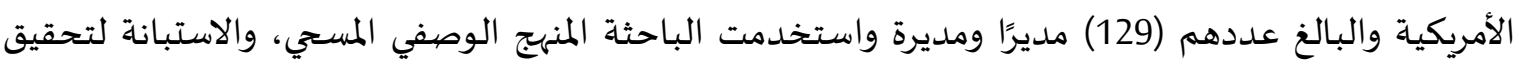

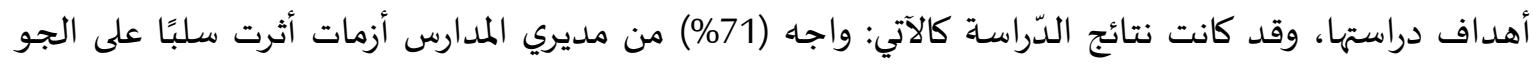

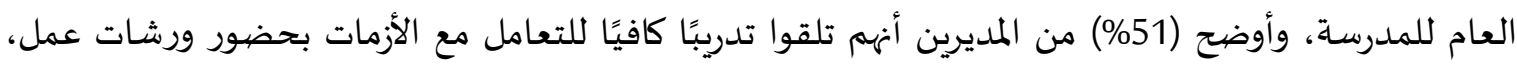

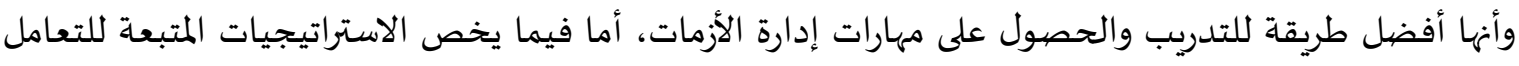

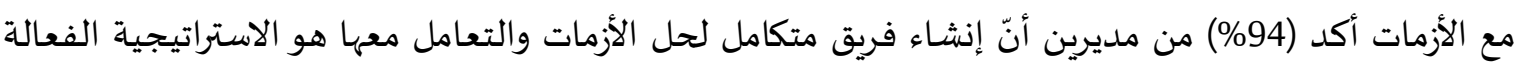
والمتبعة لديهم في المدرسـة.

التعقيب على الدراسات السابقة بعد الاطلاع على الدراسات السابقة العربية والأجنبية الخاصة في الموضوع توصل الباحث إلى أن غالبية

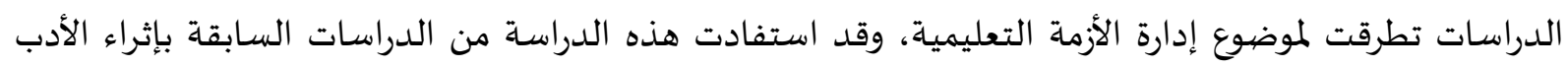

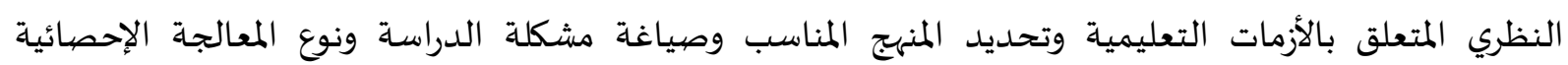

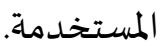
أما ما يميز هذه الدراسة عن الدراسات السابقة الأخرى فيتمثل في كونها تقع ضمن الدراسات الأولى التي تناقش درجة ممارسة مدراء المدارس الثانوية لإدارة الأزمة التعليمية في محافظة عجلون في ظل جائحة كورة فئل فورونا، وكونها من الدراسات الأولى التي ستجرى في محافظة عدجلون في أمداء المملكة الأردنية الهاشمية.

3- منهجية الدّراسـة وإجراءاتها.

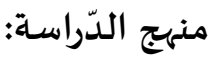

استخدمت الباحثة في هذه الدّراسة المنهج الوصفي المستي التحليلي وذلك لملاءمته لأغراض الدّراسة.

مجتمع الدراسة وعينتها: تكوّن مجتمع الدّراسة من معلمي ومعلمات المدارس الثانوية الحكومية التابعة لمديرية تربية محافظة عجلون

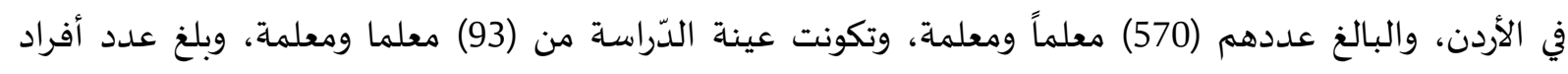

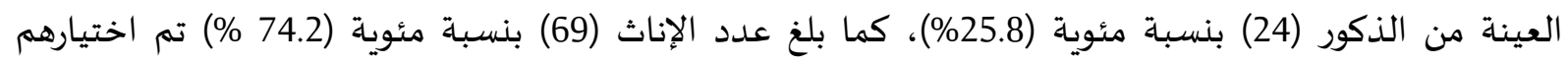

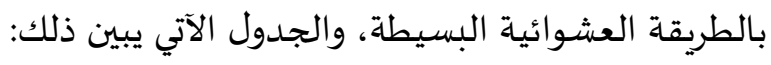


جدول (1) توزيع أفراد عينة الدراسة تبعاً للمعلومات الديمغرافية

\begin{tabular}{|c|c|c|c|}
\hline النسبة المئوية & التكرار & الفئات & المتغيرات \\
\hline 25.8 & 24 & ذكر & \multirow{2}{*}{ الجنس } \\
\hline 74.2 & 69 & أنثى & \\
\hline 14.0 & 13 & أقل من 5 سنوات & \multirow{3}{*}{ سنوات الخبرة } \\
\hline 26.9 & 25 & 5- 10 سنوات & \\
\hline 59.1 & 55 & أكثر من 10 سنوات & \\
\hline 100.0 & 93 & \multicolumn{2}{|c|}{ المجموع } \\
\hline
\end{tabular}

يظهر من جدول (1) ما يلي:

1- بلغ عدد الإناث في عينة الدراسة (69) بنسبة مئوية (74.2\%)، بينما بلغ عدد الذكور (24) بنسبة مئوية

. $(\% 25.8)$

2- بلغت أعلى نسبة مئوية لتوزيع أفردا العينة تبعاً لمتفير سنوات الخبرة (59.1\%) لسنوات (أكثر من 10 سنوات)، بينما بلغت أدنى نسبة مئوية (14.0\%) لسنوات لعئ (أقل من 5 سنوات).

أداة الدّراسة:

وذلك بعد الرجوع للدراسات السابقة والإطار النظري المتعلق بالموضوع، اعتمدت الباحثة الاستبانة كأداة

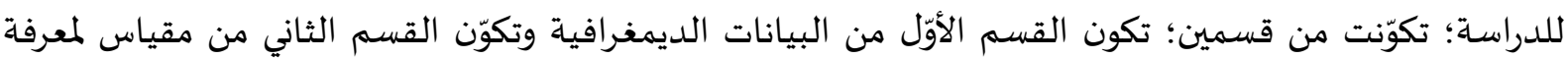

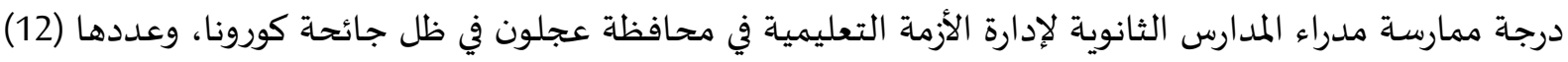

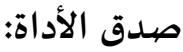

تمّ التحقق من صدق أداة الدّراسة؛ الاستبانة، للتأكد من شموليّها، وسلامة صياغتها بشكل واضح ودقيق،

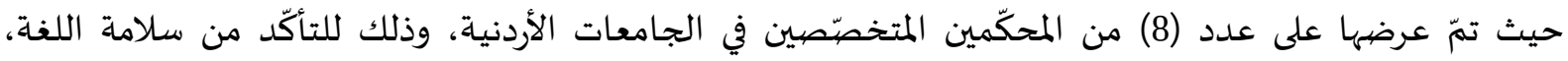

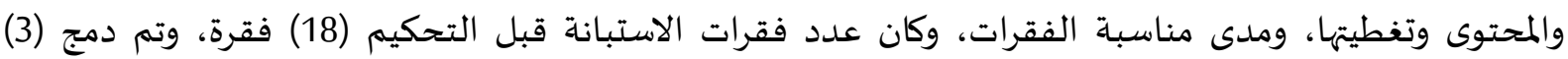

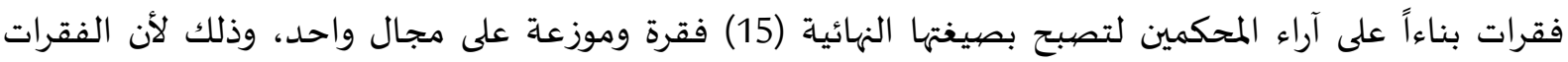

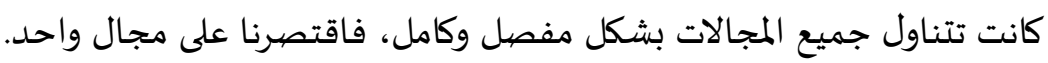

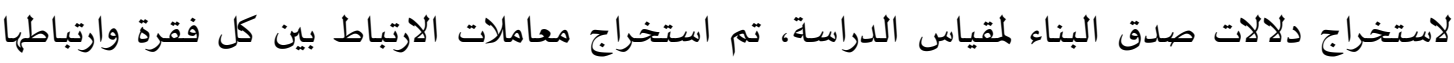

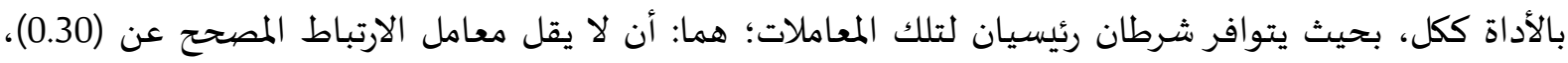
ووجود دلالة إحصائية لتلك المعاملات. والجدول (2) يبين قيم تلك المعاملان وتئات جدول (2) معاملات الارتباط بين الفقرة والدرجة الكلية

\begin{tabular}{|c|c|c|c|}
\hline معامل الارتباط* مع الأداة & رقم الفقرة & معامل الارتباط* مع الأداة & رقم الفقرة \\
\hline 0.864 & 9 & 0.804 & 1 \\
\hline 0.873 & 10 & 0.771 & 2 \\
\hline 0.851 & 11 & 0.835 & 3 \\
\hline
\end{tabular}




\begin{tabular}{|c|c|c|c|}
\hline معامل الارتباط* مع الأداة & رقم الفقرة & معامل الارتباط* مع الأداة & رقم الفقرة \\
\hline 0.848 & 12 & 0.847 & 4 \\
\hline 0.848 & 13 & 0.813 & 5 \\
\hline 0.813 & 14 & 0.830 & 6 \\
\hline \multirow[t]{2}{*}{0.787} & 15 & 0.785 & 7 \\
\hline & & 0.784 & 8 \\
\hline
\end{tabular}

(دالة إحصائيا عند مستوى الدلالة (20.05). ومن الجدول السابق (2) نجد أن جميع معاملات الارتباط كانت ذات درجات مقبولة ودالة إحصائيا، ولذلك لم يتم حذف أي من هذه الفقرات.

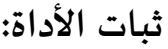

للتأكد من ثبات الأداة تم استخدام معادلة كرونباخ ألفا على عينة الدراسة، وذلك لمعرفة معامل ثبات الاتساق الداخلي لمقياس الدراسة فقد بلغت قيمته (0.966) وهي قيمة مرتفعة وكافية لإجراء الدراسة.

المعيار الإحصيائي المستخدم ولتفسير المتوسطات الحسابية لتقديرات أفراد عينة الدراسة على كل فقرة من فقرات الاستبانة؛ تم

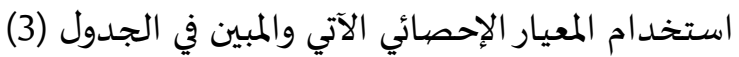
الجدول (3) المعيار الإحصائي لتفسير المتوسطات الحسابية لتقديرات أفراد عينة الدراسة على كل فقرة من فقرات الأداة

\begin{tabular}{|c|c|}
\hline درجة الموافقة & المتوسط الحسابي \\
\hline منخفضية & من 1.00 -2.33 \\
\hline متوسطة & من 2.34 -3.66 \\
\hline مرتفعة & من 3.67 - 5.00 \\
\hline
\end{tabular}

الأساليب الإحصيائية المستخدمة في الدراسـة:

للإجابة على أسئلة الدراسة واختبار صحة فرضياتها تم استخدام الأساليب والمعالجات الإحصائية المناسبة التي تم إجراؤها باستخدام الرزمة الإحصائية للعلوم الاجتماعية (SPSS)، وعلى النحو الآتي:

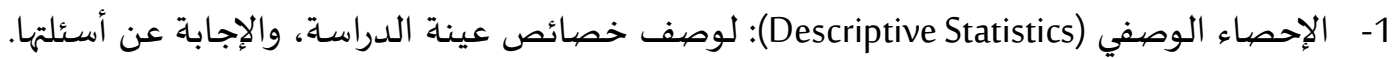
2- معامل كرونباخ ألفا لتقدير ثبات الاتساق الداخلي للأداة (Consistency Reliability). 3- تحليل التباين المتعدد لاختبار الدلالة الإحصائية للفروقات بين المتوسطات الحاتيات الحسابية لتقديرات أفراد العينة على مقياس الدراسة تبعاً لمتغير (الجنس، سنوات الخبرة). 
نتيجة السؤال الأول: ما درجة ممارسة مدراء المدارس الثانوية لإدارة الأزمة التعليمية في محافظة عجلون في

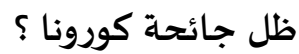

للإجابة عن هذا السؤال تم حساب المتوسطات الحسابية والانحرافات المعيارية لفقرات أداة الدراسة، جدول التالي (4) يوضح ذلك:

جدول (4) المتوسطات الحسابية والانحرافات المعيارية لتقديرات عينة الدراسة على أداة الدراسة مرتبة تنازلياً

\begin{tabular}{|c|c|c|c|c|}
\hline 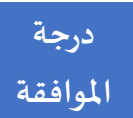 & الانحراف - المعياري & | المتوسط & 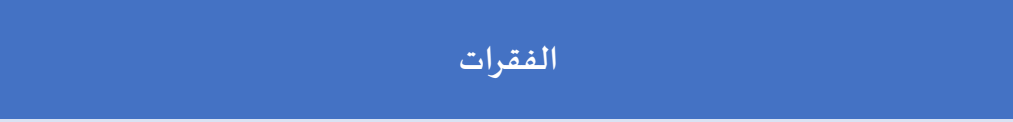 & $\hat{\imath}$ \\
\hline 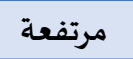 & 0.913 & 3.720 & يتابع مدير المدرسة التزام العاملين بأدوارهم أثناء وقوع الأزمة & 8 \\
\hline 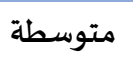 & 0.901 & 3.581 & يوجه مدير المدرسة المعلمين لاكتساب المهارات في مواجهة الأزمات & 12 \\
\hline 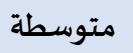 & 0.839 & 3.570 & يجمع مدير المدرسة المعلومات الكافية المتعلقة بالأزمة أثناء حدوثها & 7 \\
\hline 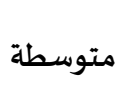 & 1.068 & 3.559 & يتبنى مدير المدرسة سياسة الباب المفتوح (التحاور) في التواصل والاتصهال بين & 9 \\
\hline 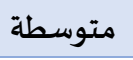 & 0.867 & 3.473 & يتابع مدير المدرسة باستمرار تداعيات الأزمة & 6 \\
\hline 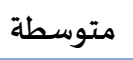 & 0.961 & 3.452 & يكون مدير المدرسة فريقاً مختصهاً للتعامل مع الأزمات بشكل دائم & 1 \\
\hline 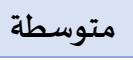 & 0.961 & 3.441 & يصمم مدير المدرسة برنامجاً زمنياً واضحاً للتعامل مع مراحل مواجهة الأزمة & 10 \\
\hline 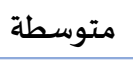 & 1.024 & 3.409 & يحصر مدير المدرسة الخسائر المادية والبشرية الناجمة عن الأزمة & 15 \\
\hline 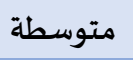 & 0.944 & 3.387 & يقيس مدير المدرسة معايير الإنجازات ومدى الاستفادة من الأزمة & 11 \\
\hline 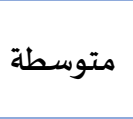 & 0.940 & 3.355 & يقوم مدير المدرسة بإعادة تشكيل الفرق واللجان الخاصة بمواجهة الأزمة طبقاً & 14 \\
\hline 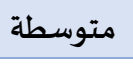 & 0.972 & 3.344 & ينظم مدير المدرسة مع المعلمين خطة لإدارة الأزمات قبل حدوثها & 3 \\
\hline 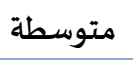 & 0.916 & 3.290 & يعمل مدير المدرسة على تقييم البرامج والخطط التي استخدمت في مواجهة الأزمة & 13 \\
\hline 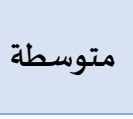 & 0.925 & 3.280 & يجمع مدير المدرسة قلاعدة بيانات عن المشكلات التي تواجه مدرسته ويوثقها & 4 \\
\hline 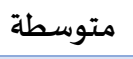 & 1.036 & 3.237 & يعقد مدير المدرسة اجتماعات دورية لبيان كيفية التعامل مع الأزمات قبل حدوثها & 5 \\
\hline 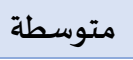 & 0.965 & 3.065 & يتنباً مدير المدرسة بالمشكلات والأزمات قبل حدوثها & 2 \\
\hline 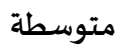 & 0.782 & 3.411 & 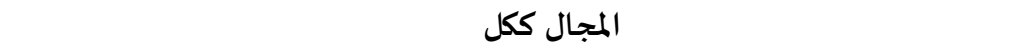 & \\
\hline
\end{tabular}

يظهر من جدول (4) أن المتوسطات الحسابية لفقرات مقياس الدراسة تراوحت بين (3.065- 3.72)، حيث

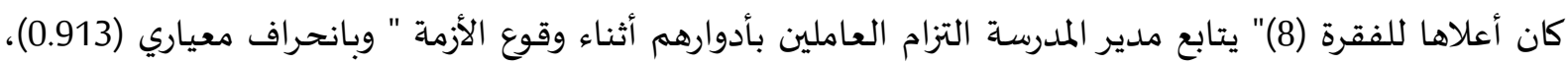
ثم يليها المتوسط الحسابي (3.581) للفقرة (12)" يوجه مدير المدرسة المعلمين لاكتساب المهارات في مواجهة الأزمات "

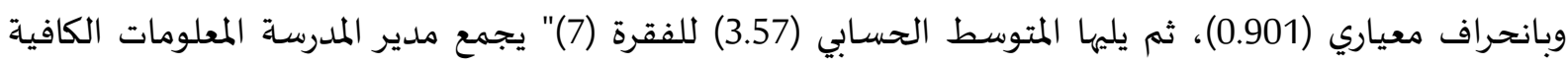

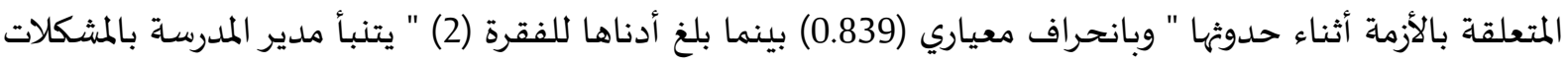

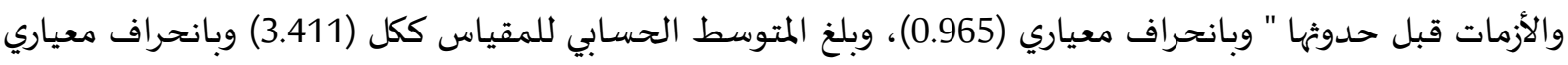

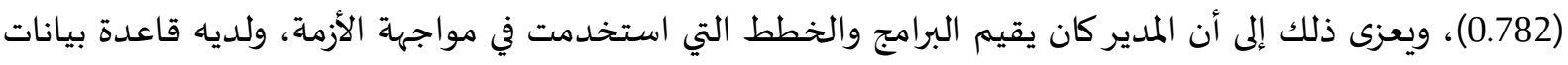

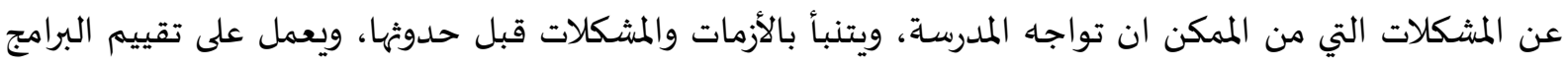

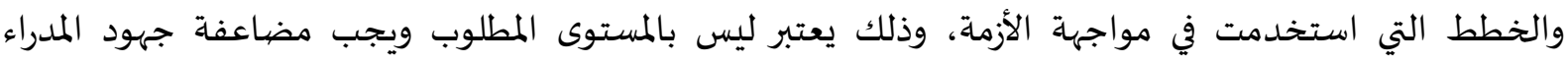

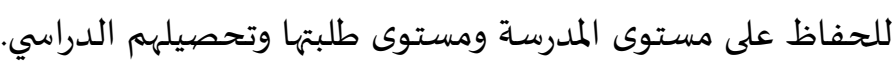


وترى الباحثة أن هذه النتيجة تتوافق مع دراسة القرني وشريف (2021) والتي بينت أن درجة توفر كفايات إدارة الأزمات لدى قائدات المدارس بمحافظة بيشة من وجهة نظر اندان المعلمات جاءت عالية في (التخطيط والتنظيم والتوجيا والمتابعة)، ودراسة مقدادي (2020) أن المتوسطات الحسابية لتقديرات معلمي الدراسات الاجتماتهاعية لدرجة تطبيق إدارة الأزمات في المدارس الحكومية في لواء قصبة إربد جاءت بدرجة كباء كبيرة، ودراسة المطيري (2019)

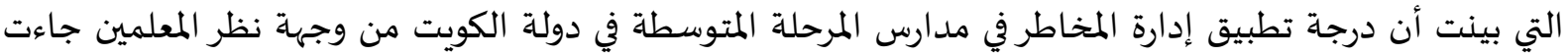
متوسطة، ودراسة المشاقبة (2018) درجة امتلاك مديري المدارس الحكومية في محافظة الزرقاء لمهارة إدارة الأزمات من وجهة نظرهم على الأداة ككل كانت مرتفعة.

نتيجة السؤال الثاني: هل توجد فروق ذات دلالة إحصائية عند مستوى (Q0.05) بين متوسطات تقديرات

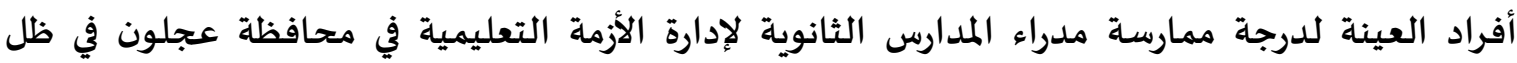

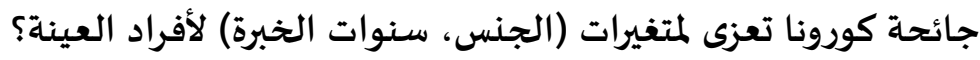

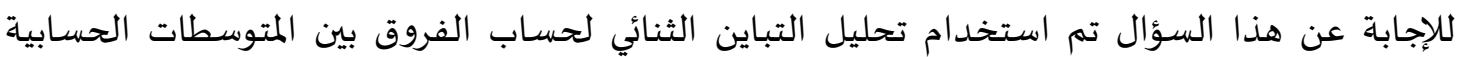

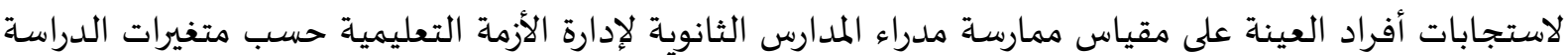
(الجنس، سنوات الخبرة)، والجداول (5) تبين ذلك. والجدول (5) نتائج تحليل التباين الثنائي للفروق بين المتوسطات الحسابية لاستجابات دات أفراد العينة على مقياس

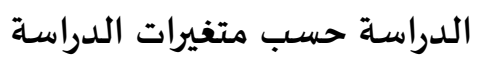

\begin{tabular}{|c|c|c|c|}
\hline الانحراف المعياري & المتوسط الحسابي & المستوى & المتغير \\
\hline 0.980 & 3.547 & ذكر & \multirow{2}{*}{ الجنس } \\
\hline 0.702 & 3.363 & أنثى & \\
\hline 0.462 & 3.738 & أقل من 5 سنوات & \multirow{3}{*}{ سنوات الخبرة } \\
\hline 0.805 & 3.453 & من 5- 10 سنوات & \\
\hline 0.818 & 3.314 & أكثر من 10 سنوات & \\
\hline
\end{tabular}

جدول (6) نتائج تحليل التباين المتعدد للفروق بين المتوسطات الحسابية لاستجابات أفراد العينة على مقياس الدراسة حسب متغيرات الدراسة

\begin{tabular}{|c|c|c|c|c|c|}
\hline الدلالة & قيمة ف & متوسط المربعات & درجات الحرية & مجموع المربعات & مصدر التباين \\
\hline 0.281 & 1.175 & 0.707 & 1 & 0.707 & الجنس \\
\hline 0.186 & 1.713 & 1.031 & 2 & 2.061 & سنوات الخبرة \\
\hline & & 0.602 & 89 & 53.543 & الخطأ \\
\hline
\end{tabular}

يتبين لنا من الجدول السابق (6) أن قيم (F) بلغت (1.175، 1.713) وهي قيم غير دالة إحصائيا عند مستوى الدلالة (as0.05) مما يدل على عدم وجود فروق ذات دلالة إحصائية بين المتوسطات الحسابية لاستجابات

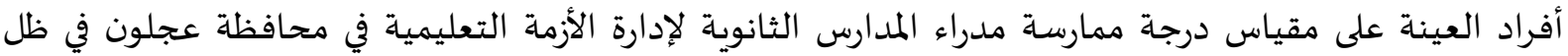

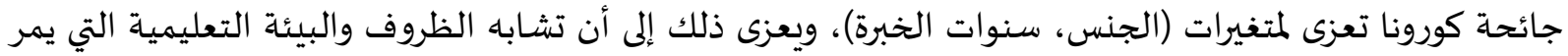

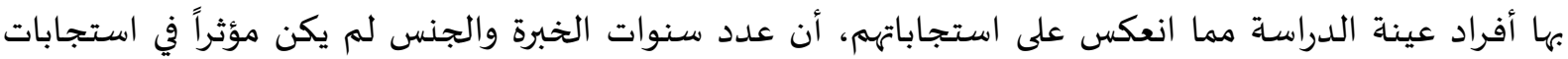


عينة الدراسة، وأن خبرة المعلمين لا تعد عاملا مهمًا في تقييم درجة ممارسة مدراء المدارس الثانوية لإدارة الأزمة التعليمية. وترى الباحثة أن هذه النتيجة تتوافق مع دراسة القرني وشريف (2021) والتي بينت عدم وجود فروق ذات

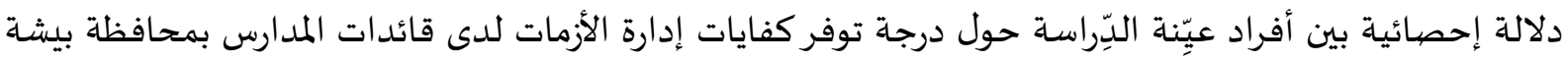

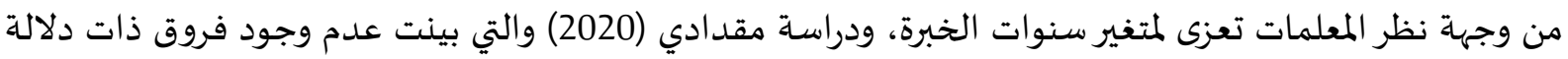

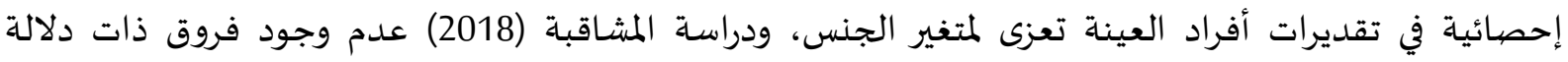

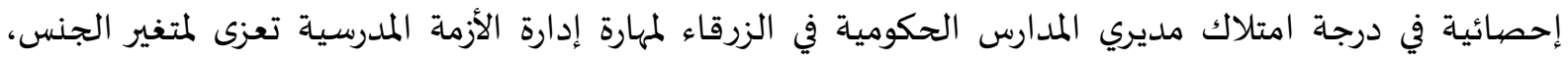

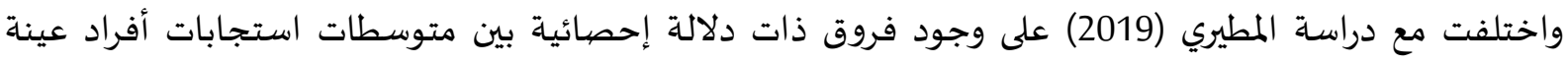
الدراسة تعزى لمتغير الجنس وسنوات درات المبري المبرة.

$$
\text { ملخص النتائج }
$$

- أظهرت النتائج أن المتوسطات الحسابية لفقرات مقياس الدراسة تراوحت بين (3.07- 3.72) وبدرجة موافقة متوسطة، حيث كان أعلاها للفقرة (8)" يتابع مدير المدرسة التزام العاملين بأدوارهم أثناء وقوع الأزمة "

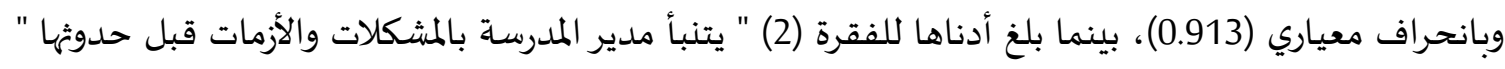
وبانحراف معياري (0.965)، وبلغ المتوسط الحسابي للمقياس ككل (3.41) وبانحراف معياري (0.782). - كما أظهرت النتائج عدم وجود فروق ذات دلالة إحصائية بين المتوسطات الحسابية لاستجابات أفراد العينة

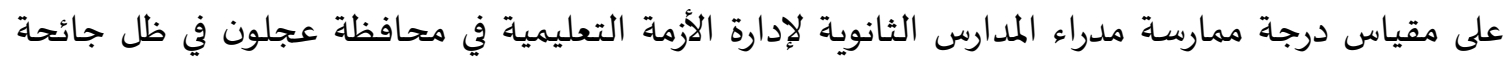

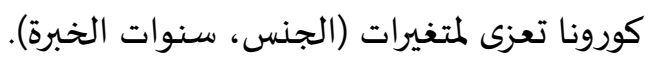

التوصيات والمقترحات.

$$
\text { في ضوء النتائج المحصلة من الدراسة توصي الباحثة وتقترح الآتي: }
$$

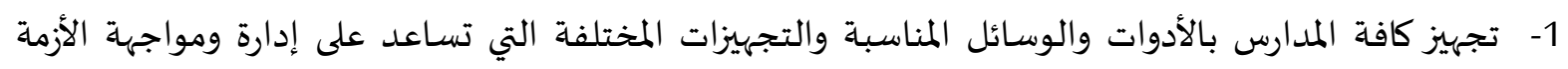
بفعالية عالية.

2- تفعيل قنوات الاتصال والتواصل المناسبة بين عناصر العملية التعليمية والإدارات المختلفة لمواجهة وإدارة

$$
\text { الأزمات بفعالية وقدرة عالية. }
$$

3- العمل على توفير جميع الإمكانات المادية والبشرية اللازمة للتعامل مع الأزمات التعليمية من خلال تخصيص وفيص المالية جزء من الميزانياة لذلك.

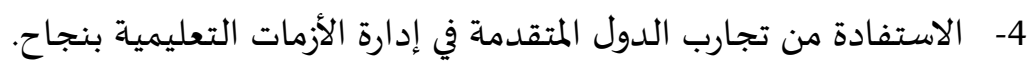

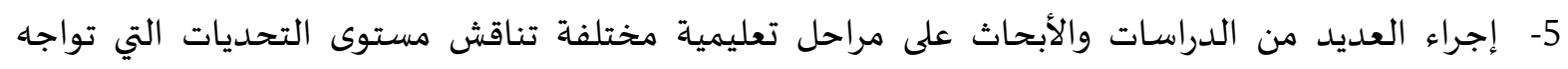

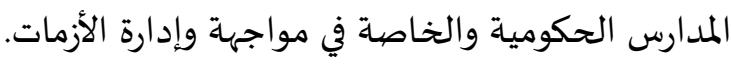


- أبو رمان، جمانه. (2021). إدارة الأزمات الكوارث والمخاطر: نهج للوقاية والعلاج والتعافي. ط (1)، عمان، الأردن: داروائل للنشروالتوزيع. ت خمانه. - خليل، عصام. (2016). واقع إدارة الأزمات في المدارس الحكومية الفلسطينية من وجهة نظر المديرين في جنوب

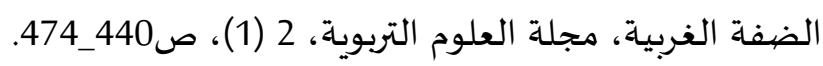
عبابنة وسعيد، عاشور ومحمد. (2018). واقع إدارة الأزمات بالجامعات الأردنية الحكومية في شمال الأردن. مجلة الجامعة الإسلامية للدراسات التربوية والنفسية، 26 (3)، 715- 742.

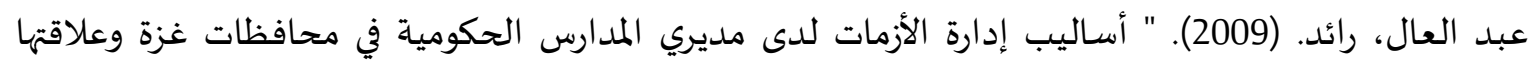

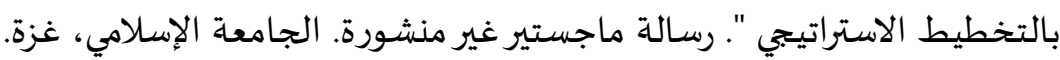

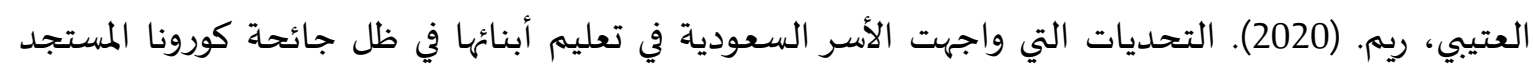
COVID - 19 عماد الدين، منى مؤتمن. (2003). إعداد مدير المدرسة لقيادة التغيير: النمط القيادي المنشود لتحقيق التعايش صايش الفاعل في القرن الواحد والعشرين. مركز الكتاب الأكاديمي. عمان.

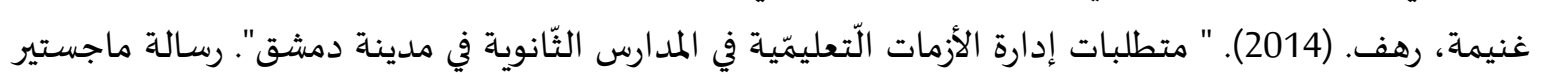

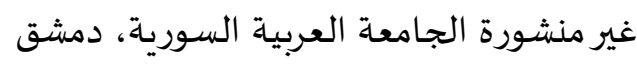
القرني، شريفة وشريف، شريف محمد. (2021). درجة توفر كفايات إدارة الأزمات لدى قائدات مدارس محافة محافظة

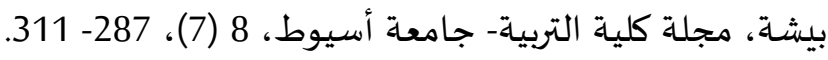
اللامي، غسان؛ والعيساوي، خالد. (2015). إدارة الأزمات: الأسس والتطبيقات، ط1)، التهبة الدار المنهجية للنشر والتوزيع. المرقطن، محمد. (2020). " متطلبات إدارة الأزمات التعليمية في ظل التعليم عن بعد " المجلة الالكترونية الشاملة متعددة التخصصيات. العدد 24 - المشاقبة، متعب. (2018). درجة امتلاك مديري المدارس الحكومية في محافظة الزرقاء لمهارة إدارة الأزمات

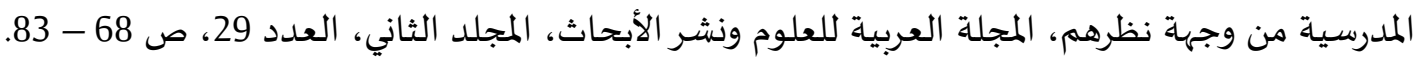

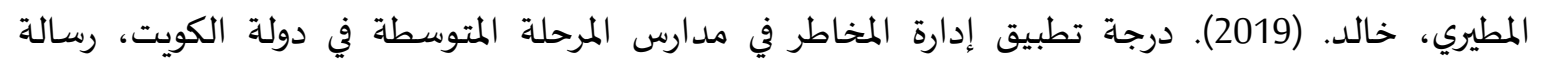
ماجستير غير منشورة، جامعة آل البيت، 2019. مقدادي، محمد. (2020). تقديرات معلمي الدراسات الاجتماعية لدرجة تطبيق إدارة الأزمات في المدارس

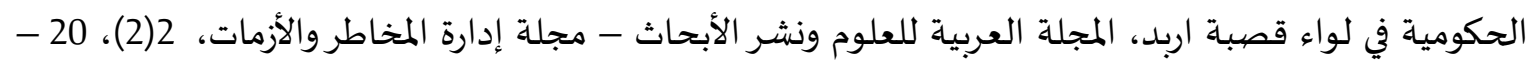

منظمة الصحة العالمية. (2020). فايروس كورونا Covid - 19 تم استرجاعاه بتاريخ 2021/7/8، متوفر على

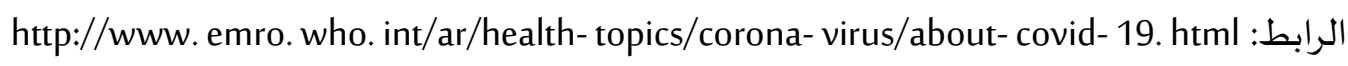
نيروخ، شهد. (2020). " درجة ممارسة إدارة الأزمات المدرسية لدى مديري المدارس الحكومية في محافظة الخليل". كلية التربية، فلسطين . نسروح. 
- اليحيوي، صبرية. (2006). إدارة الأزمات في المدارس المتوسطة الحكومية للبنات بالمدينة المنورة. مجلة جامعة الملك سعود، العلوم التربوية والدراسات الإسلامية، 19 (1)، 247- 380.

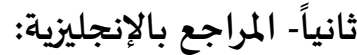

- Adams, c\& kristonis, w. (2006). An analysis of secondary school's crisis management preparedness. National doctoral student research, 1 (1), 7-10.

- Daughtry, P. (2015). Principals' Preparedness for, and Experiences of, Crisis Events at School. Retrieved in July, 8, 2021 from: https://scholarcommons. sc. edu/etd/3688.

- Hundred Organization. (2020). Quality Education for all during COVID- 19. Retrieved in July, 8, 2021 from: https://hundred. org/en/collections/quality- education- for- all- during-coronavirus.

- Kaliobi, Kazi- Haq, and Tigran, Shamis. (2020). Coronavirus emerging on educational systems around the world, the World Bank Group, retrieved on 4/27/2021, available at the following link: https://blogs. worldbank. org/ar/education.

- Ludwing, E. (2005). How to prepare for your inevitable crisis, American Banker, 34 (170).

- Margaret, Rouse. (2013). Crisis Management Plan, Department of Communication Studies, USA.

- Muro, J. \& Kottman. T (2005): Guidance and counseling in the Elementary and Middle schools: A practical Approach. Madison, low: WCB Brown \& Bench mark Publishers.

- Mustafa, Nasir. (2020). Impact of The 2019-20 Coronavirus Pandemic On Education, International Journal of Health Preferences Research.

- Oredein, A. (2010). Principals' decision- making as correlates of crisis management in south- west Nigerian secondary schools. International Journal of Pedagogies and Learning, 6 (1), 62-68.

- Stanimirov EP, Zhechev VS, Stanimirova MR (2017). Process management the case of business service companies in Bulgaria. Inquiry. Dec 22; 21). 